Proc. IMechE- Part N: Journal of Nanomaterials, Nanoengineering and Nanosystems.

Accepted September 272018

ISSN: 2397-7914 ; Online ISSN: 2397-7922. Publisher- Sage

\title{
CHEB YSHEV COLLOCATION COMPUTATION OF MAGNETO-BIOCONVECTION NANOFLUID FLOW OVER A WEDGE WITH MULTIPLE SLIPS AND MAGNETIC INDUCTION M.J. Uddin ${ }^{1 *}$, M.N. Kabir ${ }^{2}$ and O. Anwar Bég ${ }^{3}$, Y. Alginahi ${ }^{4}$
}

${ }^{1}$ Prof and Head of Mathematics Department, American International University-Bangladesh, Kuril, Dhaka, 1229, Bangladesh. Email:jashim_74@yahoo.com

${ }^{2}$ Faculty of Computer Systems \& Software Engineering, University Malaysia Pahang, 26300 Gambang, Pahang, Malaysia. Email: nomanikabir@ump.edu.my

${ }^{3}$ Aeronautical and Mechanical Engineering Department, School of Computing, Science and Engineering, Newton Building, University of Salford, M54WT, UK. Email: O.A.Beg@salford.ac.uk

${ }^{4}$ Deanship of Academic Services, Department of Computer Science, Taibah University, P.O. Box 344, Madinah, Saudi Arabia. Email: yasser.m.alginahi@ieee.org

\section{*Corresponding author}

\begin{abstract}
:
In this paper the steady two dimensional stagnation point flow of a viscous incompressible electrically conducting bio-nanofluid over a stretching/shrinking wedge in the presence of passively control boundary condition, Stefan blowing and multiple slips is numerically investigated. Magnetic induction is also taken into account. The governing conservation equations are rendered into a system of ordinary differential equations via appropriate similarity transformations. The reduced system is solved using a fast, convergent Chebyshev collocation method. The influence of selected parameters on the dimensionless velocity, induced magnetic field, temperature, nanoparticle volume fraction and density of motile microorganisms as well as on the local skin friction, local Nusselt number, local Sherwood number and density of motile microorganism numbers are discussed and presented graphically. Validation with previously published results is performed and an excellent agreement is found. The study is relevant to electromagnetic manufacturing processes involving bionano-fluids.
\end{abstract}

KEYWORDS; Electromagnetic materials processing; nano-biofluid, slip; magnetic induction; Chebyshev collocation method; Stefan blowing

\section{INTRODUCTION}

The external boundary layer flow over a two dimensional wedge is a classical problem in viscous fluid dynamics which has considerable relevance to many areas of technology including materials processing operations. Early studies of this so-called "Falkner-Skan flows" have been summarized succinctly in the monograph of Rosenhead ${ }^{1}$. These flows consider a wedge with included apex angle of $\pi \beta$ with an external pressure gradient associated with the inviscid external flow solution. Such flows introduce a "wedge parameter" which enables a number of physically viable special cases to be extracted including forward stagnation point flow, rear stagnation point flow, Blasius boundary layer flow etc. The fluids considered in Rosenhead's book were Newtonian. Numerous investigations of momentum, heat and mass transfer from wedge geometries have been communicated subsequently for non-Newtonian fluids since these abound in chemical and biotechnology operations. In many applications multi-physical effects also arise simultaneously and these may include electrical fields, magnetic fields, multi-mode heat transfer (conduction, convection and radiation), non-isothermal behavior, entropy generation, thermal stratification etc. Atalik and Sönmezler ${ }^{2}$ 
studied electrofluid boundary layer flow from a two-dimensional wedge with group theoretical methods. Abdul Gaffar et al. ${ }^{3}$ investigated numerically the coupled thermal and velocity boundary layer flow from a non-isothermal wedge geometry to magnetized Eyring-Powell non-Newtonian fluids. Rashad ${ }^{4}$ investigated hydromagnetic mixed convection slip flow of Cobalt-kerosene ferrofluid from a non-isothermal wedge under the radiative flux and wall slip effects using a influence of thermal radiation and partial slip. Olagunju ${ }^{5}$ analyzed the Falkner-Skan flow of a FENE-P viscoelastic fluid elaborating the influence of Weissenberg number and deriving a similarity solution for axisymmetric stagnation point flow. Rashidi et al. ${ }^{6}$ derived homotopy solutions for third grade differential Reiner-Rivlin convection boundary layer non-isothermal Falkner-Skan flow. Mansutti and Pontrelli ${ }^{7}$ considered non-similar solutions for Falkner-Skan flows of second grade rheological fluids. $\mathrm{Yih}^{8}$ obtained computational solutions for hydromagnetic forced convection nonisothermal Falkner-Skan flows.

In recent years, the global expansion in nanotechnology has led to a new type of fluid aimed largely at enhancing thermal engineering properties. Nanofluids constitute a significant advance in fluid dynamics technology and are synthesized by doping conventional base fluids (e.g. water, mineral oil, air, etc.) with carefully designed nano-particles. The resulting suspension achieves improved thermal conductivity and modified viscosity properties. The surface area per unit volume of nanoparticles is much larger (millions of times) than that of conventional microparticles. The number of surface atoms per unit of interior atoms of nanoparticles, is very large. These characteristics can be exploited in many complex systems including nuclear reactor cooling systems, hybrid solar power collectors, materials processing, lubrication (tribology) and medical agents. Nanofluids have infiltrated into many areas also of materials fabrication as they can be manipulated to yield more biologically friendly, sustainable and durable products. Although a considerable experimental thrust has driven nanofluid research and development, this has been reinforced with extensive theoretical and computational investigations. Nanofluid mechanics problems have been studied for steadystate, unsteady, one, two and three-dimensional configurations. A sub-set of these flows are known as similar flows which reduce the number of coordinates and often permit the reduction of non-linear coupled partial differential equations into systems of ordinary differential equations which are considerably easier to solve numerically. Yacob et al. ${ }^{9}$ studied steady nanofluid Falkner-Skan flow and heat transfer over a static/moving wedge with a prescribed surface heat flux, considering copper, alumina and titania as nanoparticles and water as the base fluid. They observed that heat transfer rate at the surface increases with the Falkner-Skan power law parameter and furthermore that dual solutions exist when the fluid and the solid surface move in opposite directions. Magnetohydrodynamic (MHD) nanofluid flows, which are of relevance to electromagnetic materials processing, also provide a rich arena for similarity models. Numerous investigations have been communicated in recent years with a variety of computational approaches including finite element methods, finite difference methods and symbolic codes for magnetic nanofluid flows ${ }^{10-20}$. Farooq et al. ${ }^{21}$ used the Mathematica package BVPh 2.0 to analyze magnetohydrodynamic Falkner-Skan flow of nano-fluid past a fixed wedge in a semi-infinite domain. Rashidi et al. ${ }^{22}$ studied entropy generation for steady MHD flow past a rotating porous disk in a nanofluid. In a series of papers ${ }^{23-26}$, various aspects of MHD flows were investigated by Sheikholeslami et al. and Ali et al.

Flows in which the boundary is stretched/contracted or moving are also pertinent to materials manufacturing. Extrusion processes, calendaring, roll coating and polymeric sheet technologies feature such flows. This assists in customizing material constitution for different applications. ${ }^{27} \mathrm{Su}$ et al. ${ }^{28}$ investigated the hydromagnetic radiative flow of Newtonian fluids from a stretching wedge with surface suction. Rashidi et $a l .{ }^{29}$ used a hybrid differential transform-Padé technique to compute the entropy generation in magnetic Von Karman swirling flow from a stretching rotating disk. Several investigations of nanofluid dynamics from stretching bodies have also been presented. Ullah et al. ${ }^{30}$ studied the effects of chemical reaction and hydrodynamic slip on unsteady MHD flow of Casson nanofluid due to wedge moving. Dogonchi and Ganji ${ }^{31}$ investigated the MHD nanofluid flow between two stretchable or shrinkable walls with thermal radiation flux, presenting semi-numerical solutions with Duan-Rach Approach (DRA) by modifying the standard Adomian Decomposition Method (ADM). 
Stagnation-point flows also constitute an interesting branch of fluid dynamics analysis. They feature in numerous situations including polymer sheet processing, rotating convection flows, vortex flows, wake cylinder flows etc. Mahapatra and Gupta $^{32}$ presented a numerical solution for steady two-dimensional stagnation point Newtonian flow from a flat deformable sheet. Gupta et al. ${ }^{33}$ employed a variational Galerkin method to simulate the MHD micropolar stagnation point flow from a permeable stretching sheet with prescribed skin friction. Khan et al. ${ }^{34}$ analyzed the stagnation-point flow of Powell-Eyring fluid with variable thermal conductivity from a stretching cylinder with a modified by homotopy analysis method. Khan et al. ${ }^{35}$ investigated stagnation-point flow of a ferrofluid from an extending sheet. Several investigations of nanofluid stagnation flows have been reported in recent years. Bég et al. ${ }^{36}$ investigated the transient nanofluid flow at the stagnation point on a rotating sphere using Adomian and homotopy method. Gireesha et al. ${ }^{37}$ used the Runge-Kutta-Fehlberg method to compute solutions for steady 2-D hydromagnetic stagnation-point flow of an electrically-conducting nanofluid from a stretching surface with induced magnetic field, melting effect and heat generation/absorption.

The above studies did not consider bioconvection phenomena. Modern developments in intelligent materials are exploring the use of swimming micro-organisms embedded in nanofluids and also nanosolids. Certain micro-organisms move via bioconvection which is a pattern formation in suspensions of microorganisms, such as bacteria and algae, due to up-swimming of the microorganisms towards a specific direction of light, gravity, chemicals, magnetic fields, oxygen etc. Gyrotactic bioconvection involves the response to a torque as the taxis. Motion is generated by a dynamic instability due to internal and mechanical energy input. The combination of nanofluids and bioconvection offers some potential in developing more biocompatible and adaptive materials for engineering systems. Different nano-particles combined with different free-swimming organisms such as ciliates and flagellates may achieve enhanced efficiencies. Nanofluid bioconvection flows have been examined by Begum et al. ${ }^{38}$ for variable thermal conductivity, by Das et al. ${ }^{39}$ for reactive gyrotactic flow in porous media and Shaw et al ${ }^{40}$ for oxytactic porous media systems. Slip effects are also relevant to certain materials operations and have been addressed in the context of nano-bioconvection boundary layer flows by Uddin et al. ${ }^{41}$ with wall injection. Further studies include Basir et al. ${ }^{42}$ who considered transient nanofluid bioconvection boundary layer enrobing flow from a stretching cylinder. The majority of these studies have emphasized the nanoscale effects of Brownian motion and thermophoresis. Kuznetsov ${ }^{43}$, and Kuznetsov and Nield ${ }^{44}$ examined the problem of natural convective boundary layer flow of nanofluid from a vertical plate and produced a formulation which renders the nanofluid particle fraction on the boundary as passively controlled. This results in a more physically realistic model for actual industrial systems. The aim of the present study is to extend the problem of Kuznetsov and Nield to the generalized Falkner-Skan wedge flow and simultaneously incorporate magnetohydrodynamic body force, magnetic induction, gyrotactic bioconvection, multiple slips (hydrodynamic, thermal, species and miro-organism) and wall injection (Stefan blowing) effects. The Buongiorno nanofluid model which utilizes Brownian and thermophoretic diffusivities is applied. The normalized ordinary differential boundary layer equations are solved with a versatile Chebyshev collocation method. Validation with published works is included. The simulations reported are of interest in electromagnetic nanofluid materials processing.

\section{MATHEMATICAL FORMULATION}

We consider steady two-dimensional stagnation-point flow of viscous incompressible electrically-conducting water-based nanofluids over a stretching/shrinking wedge with multiple slips and passively control boundary conditions. The effect of the induced magnetic field is also taken into account. The coordinates system is selected such that the $\bar{x}$-axis is along the wedge face and the $\bar{y}$-axis is perpendicular to it. At the wedge surface with $\bar{y}=0$, the temperature, $T$ and nanoparticle volume fraction, $C$ are prescribed as constant values of $T_{w}, C_{w}$ respectively. The ambient values $(\bar{y} \rightarrow \infty)$ for temperature and nanoparticle volume fraction respectively, are $T_{\infty}, C_{\infty}$. It is assumed that the velocity of the wedge surface is $\bar{u}_{w}=\lambda \sqrt{\operatorname{Re}}\left(\frac{v}{L}\right)\left(\frac{\bar{x}}{L}\right)^{m}$, where 
$\lambda$ is a constant. It is further assumed that the velocity of the external flow $\bar{u}_{e}=\sqrt{\operatorname{Re}}\left(\frac{v}{L}\right)\left(\frac{\bar{x}}{L}\right)^{m}$, where $L$ is the characteristic length. A magnetic field of strength $H o$ is applied in the direction parallel to the surface of the body (i.e., along the $\bar{x}$-axis outside the boundary layer). The effects of viscous dissipation, Joule heating and Hall effect are neglected. The electric field $(E)$ is assumed to be negligible. The electrical current in the fluid gives rise to an induced magnetic field. We assume that the normal component of the induced magnetic field $H_{2}$ vanishes at the wall and the parallel component $H_{1}$ approaches its given value $H_{o}$. The physical flow model and coordinate system are shown in Fig. 1.

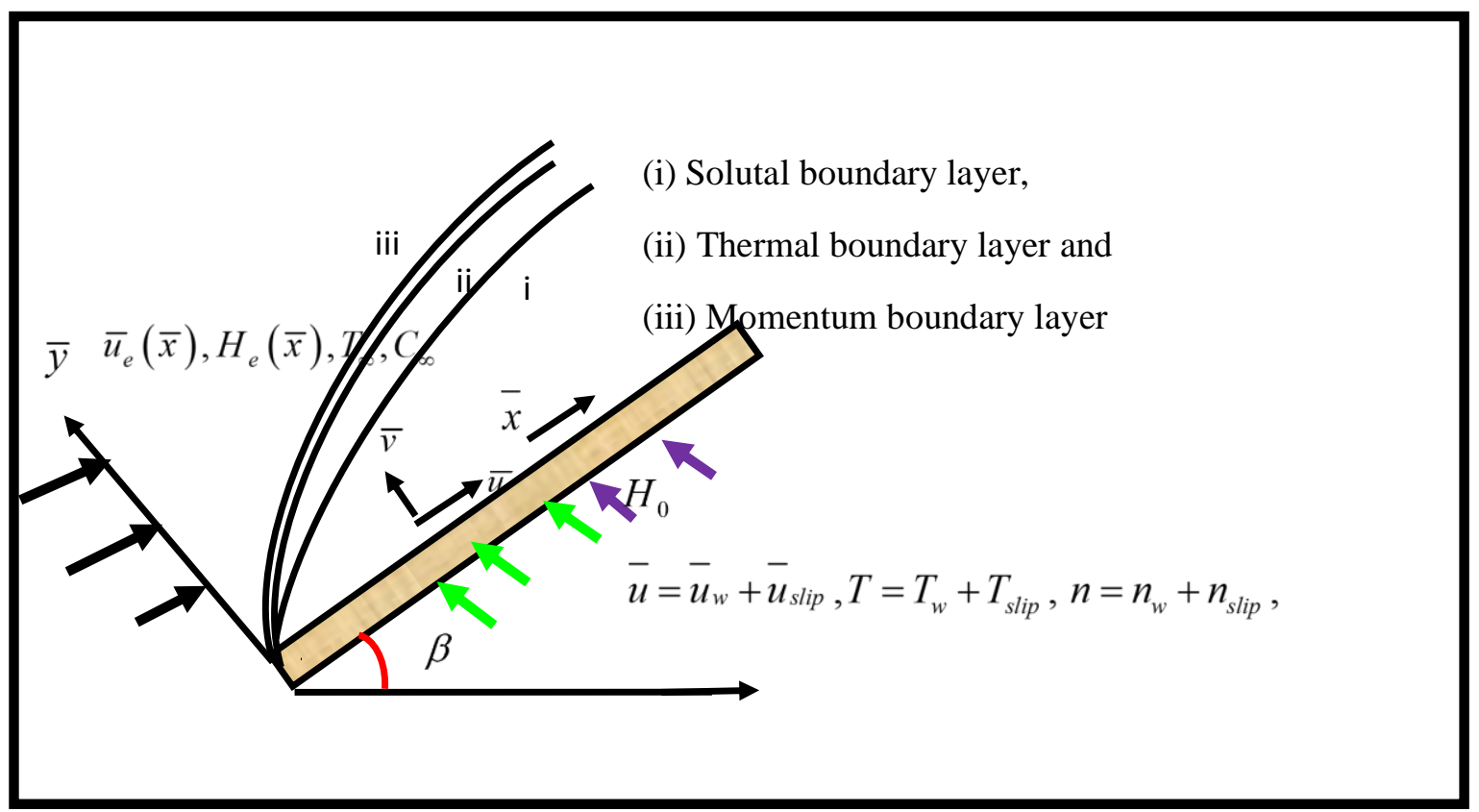

Fig. 1: Physical model and coordinate system

Fig. 1: Physical model and its coordinate system

Under these above mentioned assumptions and boundary layer approximations, the governing equations related to the conservation of mass, induced magnetic field, momentum, energy, nano-particle concentration and micro-organism species can be written as:

$$
\begin{aligned}
& \frac{\partial \bar{u}}{\partial \bar{x}}+\frac{\partial \bar{v}}{\partial \bar{y}}=0, \\
& \frac{\partial \bar{H}_{1}}{\partial \bar{x}}+\frac{\partial \bar{H}_{2}}{\partial \bar{y}}=0,
\end{aligned}
$$

$\bar{u} \frac{\partial \bar{u}}{\partial \bar{x}}+\bar{v} \frac{\partial \bar{u}}{\partial \bar{y}}-\frac{\mu_{m}}{4 \pi \rho_{f}}\left(\bar{H}_{1} \frac{\partial \bar{H}_{1}}{\partial \bar{x}}+\bar{H}_{2} \frac{\partial \bar{H}_{1}}{\partial \bar{y}}\right)=K\left(\bar{u}_{e} \frac{d \bar{u}_{e}}{d \bar{x}}-\frac{\mu_{m} \bar{H}_{e}}{4 \pi \rho_{f}} \frac{d \bar{H}_{e}}{d \bar{x}}\right)+v \frac{\partial^{2} \bar{u}}{\partial \bar{y}^{2}}$,

$$
\bar{u} \frac{\partial \bar{H}_{1}}{\partial \bar{x}}+\bar{v} \frac{\partial \bar{H}_{1}}{\partial \bar{y}}-\bar{H}_{1} \frac{\partial \bar{u}}{\partial \bar{x}}-\bar{H}_{2} \frac{\partial \bar{u}}{\partial \bar{y}}=\varsigma \frac{\partial^{2} \bar{H}_{1}}{\partial \bar{y}^{2}}
$$


$\bar{u} \frac{\partial T}{\partial \bar{x}}+\bar{v} \frac{\partial T}{\partial \bar{y}}=\alpha \frac{\partial^{2} T}{\partial \bar{y}^{2}}+\tau D_{B} \frac{\partial T}{\partial \bar{y}} \frac{\partial C}{\partial \bar{y}}+\tau\left(\frac{D_{T}}{T_{\infty}}\right)\left(\frac{\partial T}{\partial \bar{y}}\right)^{2}$,

$\bar{u} \frac{\partial C}{\partial \bar{x}}+\bar{v} \frac{\partial C}{\partial \bar{y}}=D_{B} \frac{\partial^{2} C}{\partial \bar{y}^{2}}+\left(\frac{D_{T}}{T_{\infty}}\right) \frac{\partial^{2} T}{\partial \bar{y}^{2}}$,

$\bar{u} \frac{\partial n}{\partial \bar{x}}+\bar{v} \frac{\partial n}{\partial \bar{y}}+\frac{\partial}{\partial \bar{y}}(n \tilde{v})=D_{n} \frac{\partial^{2} n}{\partial \bar{y}^{2}}$.

The magnetic induction formulation follows Sutton and Sherman. ${ }^{45}$ The boundary conditions ${ }^{46-47}$ imposed at the wedge surface and the edge of the boundary layer are:

$\bar{u}=\bar{u}_{w}(\bar{x})+\bar{u}_{\text {slip }}=\lambda \sqrt{\operatorname{Re}}\left(\frac{v}{L}\right)\left(\frac{\bar{x}}{L}\right)^{m}+\bar{u}_{\text {slip }}, \bar{v}=-\frac{D_{B}}{1-C_{w}}\left(\frac{\partial C}{\partial \bar{y}}\right), \bar{H}_{2}=0, \frac{\partial \bar{H}_{1}}{\partial \bar{y}}=0, \quad T=T_{w}+T_{\text {slip }}$,

$D_{B} \frac{\partial C}{\partial \bar{y}}+\frac{D_{T}}{T_{\infty}} \frac{\partial T}{\partial \bar{y}}=0, n=n_{w}+n_{\text {slip }} \quad$ at $\bar{y}=0$,

$\bar{u}=\bar{u}_{e}(\bar{x}) \rightarrow \sqrt{\operatorname{Re}} K\left(\frac{v}{L}\right)\left(\frac{\bar{x}}{L}\right)^{m}, \bar{H}_{1}=\bar{H}_{e}(\bar{x}) \rightarrow K \sqrt{\operatorname{Re}} \bar{H}_{0}\left(\frac{\bar{x}}{L}\right)^{m}$,

$T \rightarrow T_{\infty}, C \rightarrow C_{\infty}, n \rightarrow 0$ as $\bar{y} \rightarrow \infty$,

where $\tau=\frac{(\rho c)_{p}}{(\rho c)_{f}}$ is the ratio of nanoparticle heat capacity to the base fluid heat capacity, $\alpha$ is the thermal diffusivity, $\varsigma=\frac{1}{4 \pi \sigma}$ is magnetic diffusivity, $\rho_{f}$ is density of the fluid, $\mu_{m}$ is magnetic permeability, $D_{B}$ is the Brownian diffusion coefficient, $D_{T}$ is thermophoretic diffusion, $\lambda$ is constant with $\lambda>0$ for a stretching wedge and $\lambda<0$ for shrinking wedge, respectively, $\bar{H}_{0}$ is the value of the uniform magnetic field at infinity (upstream), $\bar{u}_{e}(\bar{x})$ and $\bar{H}_{e}(\bar{x})$ are the $\bar{x}$-velocity and $\bar{x}$-magnetic field at the edge of the boundary layer. $\bar{u}_{\text {slip }}=N_{1}(\bar{x} / L) v \frac{\partial \bar{u}}{\partial \bar{y}}$, where $N_{1}(\bar{x} / L)$ is the slip factor, $T_{\text {slip }}=D_{1}(\bar{x} / L) \frac{\partial T}{\partial \bar{y}}$, is the thermal slip, $D_{1}$ is the thermal slip factor, $n_{\text {slip }}=E_{1}(\bar{x} / L) \frac{\partial n}{\partial \bar{y}}$, is the micro-organism slip, $E_{1}(\bar{x} / L)$ is the microorganism slip factor and $\tilde{v}=\frac{\tilde{b} W_{c}}{\Delta C} \frac{\partial C}{\partial \bar{y}}$

\section{NORMALIZATION OF THE GOVERNING EQUATIONS}

The following dimensionless variables are introduced to transform Eqns. (1)-(8) into dimensionless form. $x=\frac{\bar{x}}{L}, \quad y=\frac{\bar{y} \sqrt[4]{\mathrm{Re}}}{L}, \quad u=\frac{\bar{u} L}{v \sqrt{\mathrm{Re}}}, \quad u_{e}=\frac{\bar{u}_{e} L}{v \sqrt{\mathrm{Re}}}, v=\frac{\bar{v} L}{v \sqrt[4]{\mathrm{Re}}}, \quad \theta=\frac{T-T_{\infty}}{T_{w}-T_{\infty}}$, $\phi=\frac{C-C_{\infty}}{C_{\infty}}, \chi=\frac{n}{n_{w}}, H_{1}=\frac{\bar{H}_{1}}{H_{0} \sqrt{\mathrm{Re}}}, H_{e}=\frac{\bar{H}_{e}}{H_{0} \sqrt{\mathrm{Re}}}, H_{2}=\frac{\bar{H}_{2}}{H_{0} \sqrt[4]{\mathrm{Re}}}$

We introduced the fluid stream function, $\psi$ defined as $u=\frac{\partial \psi}{\partial y}, v=-\frac{\partial \psi}{\partial x}$ and magnetic stream function, $\Phi$, defined as $H_{1}=\frac{\partial \Phi}{\partial y}, H_{2}=-\frac{\partial \Phi}{\partial x}$. Substitution into Eqns.(3)-(8) yields: 
$\frac{\partial \psi}{\partial y} \frac{\partial^{2} \psi}{\partial x \partial y}-\frac{\partial \psi}{\partial x} \frac{\partial^{2} \psi}{\partial y^{2}}-M\left(\frac{\partial \Phi}{\partial y} \frac{\partial^{2} \Phi}{\partial x \partial y}-\frac{\partial \Phi}{\partial x} \frac{\partial^{2} \Phi}{\partial y^{2}}\right)-K u_{e} \frac{d u_{e}}{d x}+M\left(K H_{e} \frac{d H_{e}}{d x}\right)-\frac{\partial^{3} \psi}{\partial y^{3}}=0$,

$\frac{\partial \psi}{\partial y} \frac{\partial^{2} \Phi}{\partial x \partial y}-\frac{\partial \psi}{\partial x} \frac{\partial^{2} \Phi}{\partial y^{2}}-\frac{\partial \Phi}{\partial y} \frac{\partial^{2} \psi}{\partial x \partial y}+\frac{\partial \Phi}{\partial x} \frac{\partial^{2} \psi}{\partial y^{2}}-\gamma \frac{\partial^{3} \Phi}{\partial y^{3}}=0$,

$\frac{\partial \psi}{\partial y} \frac{\partial \theta}{\partial x}-\frac{\partial \psi}{\partial x} \frac{\partial \theta}{\partial y}-\frac{1}{\operatorname{Pr}} \frac{\partial^{2} \theta}{\partial y^{2}}-\frac{N b}{\operatorname{Pr}} \frac{\partial \theta}{\partial y} \frac{\partial \phi}{\partial y}-\frac{N t}{\operatorname{Pr}}\left(\frac{\partial \theta}{\partial y}\right)^{2}=0$,

$\frac{\partial \psi}{\partial y} \frac{\partial \phi}{\partial x}-\frac{\partial \psi}{\partial x} \frac{\partial \phi}{\partial y}-\frac{1}{S c} \frac{\partial^{2} \phi}{\partial y^{2}}-\frac{1}{S c} \frac{N t}{N b} \frac{\partial^{2} \theta}{\partial y^{2}}=0$,

$\left[\frac{\partial \psi}{\partial y} \frac{\partial \chi}{\partial x}-\frac{\partial \psi}{\partial x} \frac{\partial \chi}{\partial y}\right]+\frac{P e}{L b} \frac{\partial}{\partial y}\left[\chi \frac{\partial \phi}{\partial y}\right]-\frac{1}{L b} \frac{\partial^{2} \chi}{\partial y^{2}}=0$

The boundary conditions Eqn.(8) become:

$\frac{\partial \psi}{\partial y}=\lambda x^{m}+\frac{N_{1}(x) v \operatorname{Re}^{1 / 4}}{L} \frac{\partial^{2} \psi}{\partial y^{2}}, \frac{\partial \psi}{\partial x}=\frac{s}{S c} \frac{\partial \phi}{\partial y}, \frac{\partial \Phi}{\partial y}=0, \frac{\partial \Phi}{\partial x}=0, \theta=1+\frac{D_{1}(x) \operatorname{Re}^{1 / 4}}{L} \frac{\partial \theta}{\partial y}$,

$N b \frac{\partial \phi}{\partial y}+N t \frac{\partial \theta}{\partial y}=0, \chi=1+\frac{E_{1}(x) \operatorname{Re}^{1 / 4}}{L} \frac{\partial \chi}{\partial y}$ at $y=0$

$\frac{\partial \psi}{\partial y}=K x^{m}, \frac{\partial \Phi}{\partial y}=K x^{m}, \theta \rightarrow 0, \phi \rightarrow 0, \quad \chi \rightarrow 0$ as $y \rightarrow \infty$.

To further simplify the boundary value problem the following coordinate transformations are developed using Lie group analysis:

$$
\eta=x^{\frac{m-1}{2}} y, \psi=x^{\frac{m+1}{2}} f(\eta), \Phi=x^{\frac{m+1}{2}} h(\eta), \theta=\theta(\eta), \phi=\phi(\eta), \chi=\chi(\eta)
$$

Here $\eta$ is the similarity independent variable and $f(\eta), h(\eta), \theta(\eta), \phi(\eta)$ and $\chi(\eta)$ are similarity dependent variables for stream function, magnetic stream function, temperature, nano-particle concentration and microorganism density function, respectively. Using the similarity transformations of Eqn. (16) in Eqns. (9)-(12), we obtain the following coupled system of nonlinear ordinary differential equations:

$$
\begin{aligned}
& f^{\prime \prime \prime}+\frac{m+1}{2}\left[f f^{\prime \prime}-M h h^{\prime \prime}\right]+m\left(K-f^{\prime 2}\right)-m M\left(K-h^{\prime 2}\right)=0, \\
& \gamma h^{\prime \prime \prime}+\frac{m+1}{2}\left[f h^{\prime \prime}-f^{\prime \prime} h\right]=0, \\
& \theta^{\prime \prime}+\left(\frac{m+1}{2}\right) \operatorname{Pr} f \theta^{\prime}+N b \theta^{\prime} \phi^{\prime}+N t \theta^{\prime 2}=0, \\
& \phi^{\prime \prime}+\left(\frac{m+1}{2}\right) S c f \phi^{\prime}+\frac{N t}{N b} \theta^{\prime \prime}=0, \\
& \chi^{\prime \prime}-\operatorname{Pe}\left(\phi^{\prime} \chi^{\prime}+\chi \phi^{\prime \prime}\right)+\left(\frac{m+1}{2}\right) L b f \chi^{\prime}=0 .
\end{aligned}
$$

The transformed boundary conditions now become: 
$f(0)=\frac{2 s}{(m+1) S c} \phi^{\prime}(0), f^{\prime}(0)=\lambda+a f^{\prime \prime}(0), h(0)=h^{\prime \prime}(0)=0, \theta(0)=1+b \theta^{\prime}(0)$,

$N b \phi^{\prime}(0)+N t \theta^{\prime}(0)=0, \chi(0)=1+d \chi^{\prime}(0)$

$f^{\prime}(+\infty)-K=h^{\prime}(+\infty)-K=\theta(+\infty)=\phi(+\infty)=\chi(+\infty)$.

The dimensionless parameters in Eqns. (17)-(22) are defined as $\operatorname{Pr}=\frac{v}{\alpha}$ (Prandtl number), $M=\frac{\mu_{m} H_{0}^{2} L^{2}}{4 \pi \rho v^{2}}$ (magnetic field), $\gamma=\frac{\varsigma}{v}$ (reciprocal of magnetic Prandtl number), $N b=\frac{\tau D_{B} C_{\infty}}{\alpha}$ (Brownian motion), $N t=\frac{\tau D_{T}\left(T_{w}-T_{\infty}\right)}{\alpha T_{\infty}} \quad$ (thermophoresis), $S c=\frac{v}{D_{B}}$ (bioconvection $\quad$ Schmidt number), $S=\frac{C_{\infty}}{1-C_{w}} \quad$ (Stefan blowing), $\quad a=\frac{\operatorname{Re}^{1 / 4}}{L} N_{1}(x) x^{\frac{m-1}{2}}$ (velocity slip), $\quad b=\frac{D_{1}(x) \operatorname{Re}^{1 / 4}}{L} x^{\frac{m-1}{2}}$ (thermal slip), $\quad d=\frac{E_{1}(x) \operatorname{Re}^{1 / 4}}{L} x^{\frac{m-1}{2}}$ (microorganism slip), $P e$ is bioconvection Peclet number, $L b=\frac{v}{D_{n}}$ (bioconvection Lewis number), $\mathrm{Sc}=\frac{v}{D_{B}}$ Schmidt number and $m=\beta /[2-\beta]$ ) is the Hartree wedge power-law parameter.

Engineering gradient quantities of interest are the skin friction coefficient $C_{f \bar{x}}$, the local Nusselt number $N u_{\bar{x}}$, the local Sherwood number $S h_{\bar{x}}$ and local micro-organism mass transfer rate, $N n_{\bar{x}}$ which take the following definitions:

$C_{f \bar{x}}=\frac{2 \mu}{\rho \bar{u}_{e}^{2}}\left(\frac{\partial \bar{u}}{\partial \bar{y}}\right)_{\bar{y}=0}, N u_{\bar{x}}=\frac{-\bar{x}}{T_{w}-T_{\infty}}\left(\frac{\partial T}{\partial \bar{y}}\right)_{\bar{y}=0}, S h_{\bar{x}}=\frac{-\bar{x}}{C_{w}-C_{\infty}}\left(\frac{\partial C}{\partial \bar{y}}\right)_{\bar{y}=0}, N n_{\bar{x}}=\frac{-\bar{x}}{n_{w}}\left(\frac{\partial n}{\partial \bar{y}}\right)_{\bar{y}=0}$.

By using non-dimensionless variables in Eqn.(9) and Eqn.(23), we obtain:

$\operatorname{Re}_{\bar{x}}^{1 / 2} C_{f_{\bar{x}}}=f^{\prime \prime}(0), \operatorname{Re}_{\bar{x}}^{-1 / 2} N u_{\bar{x}}=-\theta^{\prime}(0), \operatorname{Re}_{\bar{x}}^{-1 / 2} S h_{\bar{x}}=-\frac{\phi^{\prime}(0)}{\phi(0)}, \operatorname{Re}_{\bar{x}}^{-1 / 2} N n_{\bar{x}}=-\chi^{\prime}(0)$

where $\operatorname{Re}_{\bar{x}}=\bar{u}_{e} \bar{x} / v$ is the local Reynolds number based on free stream velocity.

\section{COMPUTATIONAL SOLUTION WITH CHEBYCHEV COLLOCATION}

Transformation of the original boundary value problem from partial differential to ordinary differential form defined by Eqns. (17)-(21) with the boundary conditions (22) reduces the complexity of the problem significantly, although nonlinearity is still retained. This allows a variety of different computational techniques to be employed including successive linearization, Keller box finite differences, cubic splines, finite elements and other algorithms. Here we elect to apply the Chebyshev collocation method which is available in MATLAB symbolic software and has very high accuracy and convergence characteristics. ${ }^{48}$ It can be used to solve the nonlinear ordinary differential equations (ODEs) efficiently. To proceed with Chebyshev collocation method, the ODEs which are of higher order are first transformed into second order ODEs as follows. Suppose that $F_{1}=f, F_{2}=f^{\prime}, F_{3}=h, F_{4}=h^{\prime}, F_{5}=\theta, F_{6}=\phi, F_{7}=\chi$. The ODEs Eqns. (17)-(21) can be formulated as the following system of ODEs with these new variables: 


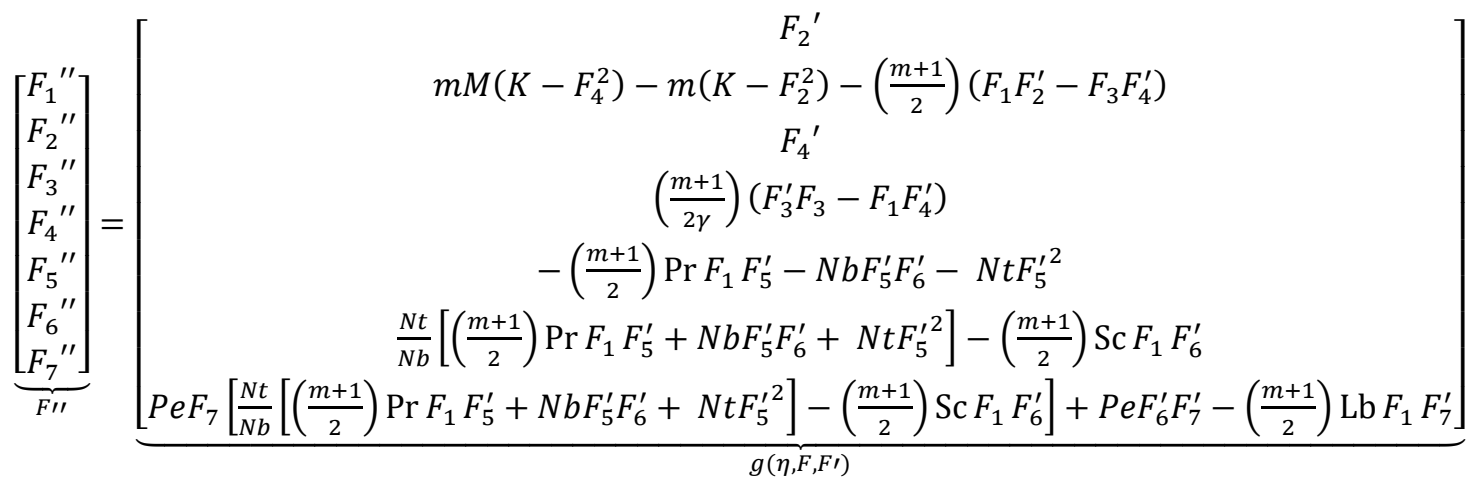

where $F^{\prime \prime}$ can be considered as a function of $\eta, F:=\left[F_{1}, F_{2}, F_{3}, F_{4}, F_{5}, F_{6}, F_{7}\right]^{T}$ and $F^{\prime}$. Using the new set of variables, the boundary conditions in Eqn. (22) can also be transformed to:

$$
\left.\begin{array}{c}
F_{1}(0)=\frac{2 s}{(m+1) S c} F_{6}(0) \\
F_{2}(0)=\lambda+a F_{2}^{\prime}(0) \\
F_{3}(0)=0 \\
F_{4}^{\prime}(0)=0 \\
F_{5}(0)=1+d F_{5}^{\prime}(0) \\
F_{6}^{\prime}(0)=-\frac{N t F_{5}^{\prime}(0)}{N b} \\
F_{2}(\infty)=K \\
F_{4}(\infty)=K \\
F_{6}(\infty)=0 \\
F_{7}(\infty)=0
\end{array}\right\}
$$

The domain of ODEs is discretized with $n$-Chebyshev collocation points $x_{\mathrm{j}}$ in the Chebyshev domain $[-1,1]$ where $x_{j}=\cos (j \pi / n)$. The derivative of $F$ can be computed using Chebyshev derivative $D F$ where $D$ is an $(n+1) \times(n+1)$ matrix with:

$$
\left.\begin{array}{c}
D_{00}=\frac{2 n^{2}+1}{6} \\
D_{n n}=-\frac{2 n^{2}+1}{6} \\
D_{j j}=\frac{-x_{j}}{2\left(1-x_{j}^{2}\right)} \quad \text { for } j=1, \ldots, n-1 \\
D_{i j}=\left(\frac{c_{i}}{c_{j}}\right) \frac{(-1)^{i+j}}{\left(x_{i}-x_{j}\right)} \text { for } \mathrm{i} \neq j, i, j=1, \ldots, n-1
\end{array}\right\} c_{i}=\left\{\begin{array}{ll}
2 & i=0 \text { or } N \\
1 & \text { otherwise }
\end{array}\right\}
$$

The second derivative of $F$ is approximated by $D^{2} F$ with $D^{2}=D \times D$. Using Chebyshev collocation on Eqn. (25), a system of 7(n+1) nonlinear equations can be deduced. We note that the actual physical range $\eta$ is $[0$, $\infty$ ]. It is found that $\eta=10$ makes a sufficient representation of the upper boundary $\eta=\infty$. The Chebyshev collocation domain [-1 1$]$ needs to be mapped on the physical domain $[0,10]$ where mapping is performed according to:

$x=\frac{\eta-5}{5}$

Eqn. (25) is finally formulated in the Chebyshev domain as:

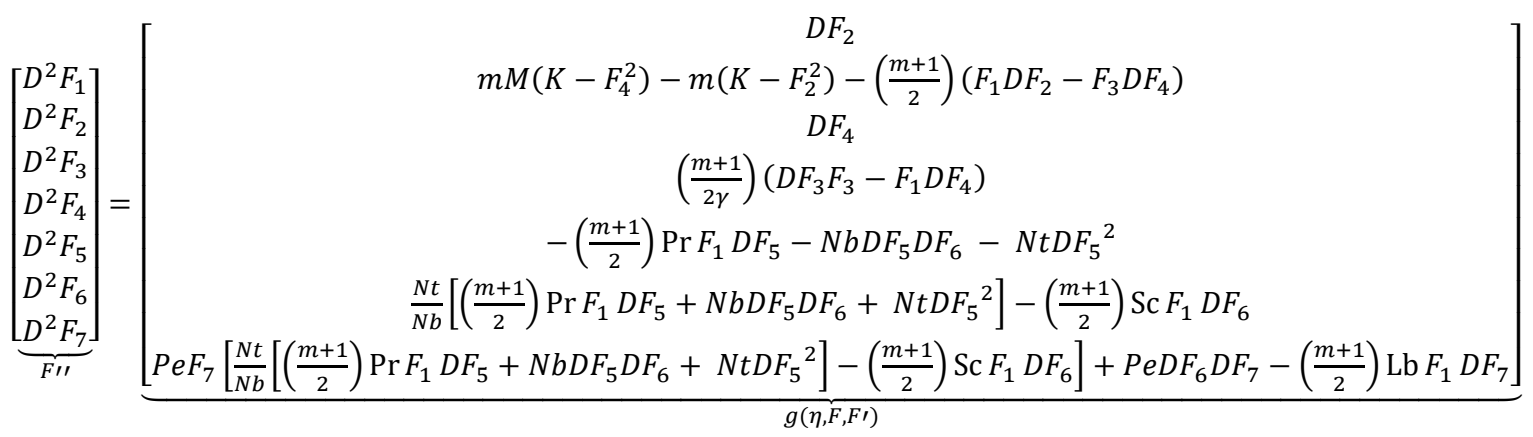


The boundary conditions are derived as

$$
\left.\begin{array}{c}
F_{1}(0)=\frac{2 s}{(m+1) S c} F_{6}(0) \\
F_{2}(0)=\lambda+0.2 a D F_{2}(0) \\
F_{3}(0)=0 \\
D F_{4}(0)=0 \\
F_{5}(0)=1+0.2 d D F_{5}(0) \\
D F_{6}(0)=-\frac{N t D F_{5}(0)}{N b} \\
F_{2}(n)=K \\
F_{4}(n)=K \\
F_{6}(n)=0 \\
F_{7}(n)=0
\end{array}\right\}
$$

The first equation of Eq. (29) can be expanded as:

$D^{2} F_{1}=\left[\begin{array}{cccc}D_{00}^{2} & D_{01}^{2} & \cdots & D_{0 n}^{2} \\ D_{10}^{2} & D_{11}^{2} & \cdots & D_{1 n}^{2} \\ \vdots & \vdots & & \vdots \\ D_{n 0}^{2} & D_{n 1}^{2} & \cdots & D_{n n}^{2}\end{array}\right]\left[\begin{array}{c}F_{1,0} \\ F_{1,1} \\ \vdots \\ F_{1, n}\end{array}\right]=\left[\begin{array}{cccc}D_{00} & D_{01} & \cdots & D_{0 n} \\ D_{10} & D_{11} & \cdots & D_{1 n} \\ \vdots & \vdots & \vdots & \vdots \\ D_{n 0} & D_{n 1} & \cdots & D_{n n}\end{array}\right]\left[\begin{array}{c}F_{2,0} \\ F_{2,1} \\ \vdots \\ F_{2, n}\end{array}\right]$

This can be re-written as

$\left[\begin{array}{cccc}D_{00}^{2} & D_{01}^{2} & \cdots & D_{0 n}^{2} \\ D_{10}^{2} & D_{11}^{2} & \cdots & D_{1 n}^{2} \\ \vdots & \vdots & \vdots & \vdots \\ D_{n 0}^{2} & D_{n 1}^{2} & \cdots & D_{n n}^{2}\end{array}\right]\left[\begin{array}{c}F_{1,0} \\ F_{1,1} \\ \vdots \\ F_{1, n}\end{array}\right]=\left[\begin{array}{c}D_{00} F_{2,0}+D_{01} F_{2,1}+\cdots+D_{0 n} F_{2, n} \\ D_{10} F_{2,0}+D_{11} F_{2,1}+\cdots+D_{1 n} F_{2, n} \\ \vdots \\ D_{n 0} F_{2,0}+D_{n 1} F_{2,1}+\cdots+D_{n n} F_{2, n}\end{array}\right]$

Moreover, the boundary conditions in Eqn. (30) need to be incorporated into the matrix set in the equations. We place the boundary conditions at the appropriate (boundary) positions by substituting corresponding discretized equations in Eqn. (29). For Eqn. (32), the first equation is replaced by the corresponding boundary equation in Eq. (29):

$$
\left[\begin{array}{cccc}
1 & 0 & \cdots & 0 \\
D_{10}^{2} & D_{11}^{2} & \cdots & D_{1 n}^{2} \\
\vdots & \vdots & \vdots & \vdots \\
D_{(n-1) 0}^{2} & D_{(n-1) 1}^{2} & \cdots & D_{(n-1) n}^{2} \\
D_{n 0} & D_{n 0} & \cdots & D_{n 0}
\end{array}\right]\left[\begin{array}{c}
F_{1,0} \\
F_{1,1} \\
\vdots \\
F_{1, n-1} \\
F_{1, n}
\end{array}\right]=\left[\begin{array}{c}
\frac{2 s}{(m+1) S c} F_{6,0} \\
D_{10} F_{2,0}+D_{11} F_{2,1}+\cdots+D_{1 n} F_{2, n} \\
\vdots \\
D_{(n-1) 0} F_{2,0}+D_{(n-1) 1} F_{2,1}+\cdots+D_{(n-1) n} F_{2, n} \\
D_{n 0} F_{2,0}+D_{n 1} F_{2,1}+\cdots+D_{n n} F_{2, n}
\end{array}\right]
$$

With this procedure, we set all the boundary conditions for $D^{2} F_{2}, D^{2} F_{3}, \ldots, D^{2} F_{7}$ in Eqn. (29) which in turn, produces a large nonlinear system of $7(n+1)$ equations with $7(n+1)$ unknowns. The system can be solved by an iterative method. In our case, the system has been solved using the MATLAB trust-region-reflective algorithm fsolve. Finally the solution is transformed back to the physical domain by the relation:

$\eta=5 x+5$

\section{VALIDATION, COMPUTATIONAL RESULTS AND DISCUSSION}

In order to obtain clear insights into the general nonlinear model developed, computational tests were conducted using different values of the emerging parameters. In the simulations, we consider a water-based 
nanofluid with the following prescribed parametric values: $\operatorname{Pr}=6.8$ (water), $S c=K=1, L b=P e=2, N b=N t=$ 0.1 and $\gamma=M=0.5$. The other default values are $a=b=d=\lambda=m=0.5$ unless otherwise mentioned. Figs. 2-11 are provided to illustrate the results. The dimensionless velocity $f^{\prime}(\eta)$, induced magnetic field $h^{\prime}(\eta)$, temperature $\theta(\eta)$, nanoparticle volume fraction (concentration) $\phi(\eta)$ and motile micro-organism density function $\chi(\eta)$ are plotted against transverse similarity coordinate, $\eta$. These solutions are especially interesting because $f^{\prime}(\eta) \rightarrow K, h^{\prime}(\eta) \rightarrow K, \theta(\eta) \rightarrow 0, \phi(\eta) \rightarrow 0$ and $\chi(\eta) \rightarrow 0$ as $\eta \rightarrow \infty$, which were described by Eqn. (22) implies that $f^{\prime}(\eta), \phi(\eta), h^{\prime}(\eta), \theta(\eta), \phi(\eta)$ and $\chi(\eta)$ tend towards zero when $\eta \rightarrow 10$ (i.e., $\eta$ is large enough) which can be established by the figures as a plausible demonstration of the model verification and specification of a sufficiently large infinity boundary condition in the computational domain. Our solutions $f^{\prime}(\eta), \phi(\eta), h^{\prime}(\eta)$, $\theta(\eta), \phi(\eta)$ and $\chi(\eta)$ at $\eta=10$ have the accuracy of the order of $\mathrm{O}\left(10^{-10}\right)$. Table 1 shows the present collocation results and the previous results obtained by Jafar et al. ${ }^{49}$ for $\mathrm{m}=1$ i.e. forward stagnation point flow adjacent to a vertical plate. Table 2 provides the comparison of the present collocation results with previous results obtained by $\mathrm{Kuo}^{50}$ for $\mathrm{m}=1$. For both cases, excellent correlation is achieved. Table $\mathbf{3}$ is provided to show the different values of $f^{\prime \prime}(0),-\theta^{\prime}(0),-\phi^{\prime}(0) / / \phi(0)$ and $-\chi^{\prime}(0)$ for different values of $a, b, d, \lambda$ and $m$. This data may also provide a benchmark for verification of the new general model solutions in future studies with alternative numerical methods.

Table 1: Comparison of the value of the friction factor $f^{\prime \prime}(0)$.

\begin{tabular}{|c|c|c|}
\hline$m$ & $\begin{array}{c}\text { Jafar } \text { et al. }^{49} \\
\text { [Keller Box Method] }\end{array}$ & $\begin{array}{c}\text { Present } \\
\text { [Collocation method] }\end{array}$ \\
\hline 1 & 1.2326 & 1.232587662 \\
\hline
\end{tabular}

Table 2: Comparison of the value of the friction factor $-\theta^{\prime}(0)$.

\begin{tabular}{|c|c|c|}
\hline$m$ & $\begin{array}{c}\text { Kuo }^{50} \\
{[\mathrm{DTM}]}\end{array}$ & $\begin{array}{c}\text { Present } \\
\text { [Collocation method] }\end{array}$ \\
\hline 1 & 1.1147 & 1.1138 \\
\hline
\end{tabular}

Table 3: Values of $f^{\prime \prime}(0),-\theta^{\prime}(0),-\phi^{\prime}(0) / \phi(0)$ and $-\chi^{\prime}(0)$ for different values of $a, b, d, \lambda$ and $m$

\begin{tabular}{|c|c|c|c|c|c|c|c|c|c|}
\hline$S$ & $a$ & $b$ & $d$ & $\lambda$ & $m$ & $f^{\prime \prime}(0)$ & $-\theta^{\prime}(0)$ & $-\phi^{\prime}(0) / \phi(0)$ & $-\chi^{\prime}(0)$ \\
\hline-1 & \multirow{3}{*}{0} & 0.5 & 0.5 & 0.5 & 0.5 & 0.2828 & 0.3144 & 0.3714 & 0.4112 \\
\hline 0 & & 0.5 & 0.5 & 0.5 & 0.5 & 0.3923 & 0.8208 & 1.8473 & -0.2894 \\
\hline 1 & & 0.5 & 0.5 & 0.5 & 0.5 & 1.1062 & 1.7116 & 91.053 & 0.2617 \\
\hline-1 & \multirow{3}{*}{1} & 0.5 & 0.5 & 0.5 & 0.5 & 0.1824 & 0.3471 & 0.4214 & 0.4256 \\
\hline 0 & & 0.5 & 0.5 & 0.5 & 0.5 & 0.2287 & 0.8857 & 2.1577 & -0.3274 \\
\hline 1 & & 0.5 & 0.5 & 0.5 & 0.5 & 0.348 & 1.7144 & 82.2943 & 0.325 \\
\hline-1 & 0.5 & \multirow{3}{*}{0.1} & 0.5 & 0.5 & 0.5 & 0.218600 & 0.352300 & 0.361000 & 0.456800 \\
\hline 0 & 0.5 & & 0.5 & 0.5 & 0.5 & 0.291400 & 1.319100 & 2.047600 & -1.114300 \\
\hline 1 & 0.5 & & 0.5 & 0.5 & 0.5 & 0.813400 & 8.530100 & 6056.90 & 0.0908 \\
\hline-1 & 0.5 & \multirow{2}{*}{1} & 0.5 & 0.5 & 0.5 & 0.227100 & 0.311800 & 0.460600 & 0.382000 \\
\hline 0 & 0.5 & & 0.5 & 0.5 & 0.5 & 0.291400 & 0.603300 & 2.049600 & 0.028900 \\
\hline
\end{tabular}




\begin{tabular}{|c|c|c|c|c|c|c|c|c|c|}
\hline 1 & 0.5 & & 0.5 & 0.5 & 0.5 & 0.435600 & 0.865700 & 21.680400 & 0.431400 \\
\hline-1 & 0.5 & 0.5 & \multirow{3}{*}{0} & 0.5 & 0.5 & 0.222300 & 0.334600 & 0.402100 & 0.531500 \\
\hline 0 & 0.5 & 0.5 & & 0.5 & 0.5 & 0.291400 & 0.863700 & 2.048500 & -0.273000 \\
\hline 1 & 0.5 & 0.5 & & 0.5 & 0.5 & 0.531900 & 1.713800 & 84.090400 & 0.368100 \\
\hline-1 & 0.5 & 0.5 & \multirow{3}{*}{1} & 0.5 & 0.5 & 0.222300 & 0.334600 & 0.402100 & 0.347000 \\
\hline 0 & 0.5 & 0.5 & & 0.5 & 0.5 & 0.291400 & 0.863700 & 2.048500 & -0.375500 \\
\hline 1 & 0.5 & 0.5 & & 0.5 & 0.5 & 0.531900 & 1.713800 & 84.089400 & 0.269000 \\
\hline-1 & 0.5 & 0.5 & 0.5 & \multirow{3}{*}{-0.5} & 0.5 & 0.570200 & 0.149400 & 0.151400 & 0.345000 \\
\hline 0 & 0.5 & 0.5 & 0.5 & & 0.5 & 0.673100 & 0.489700 & 0.741100 & 0.033400 \\
\hline 1 & 0.5 & 0.5 & 0.5 & & 0.5 & 1.557800 & 1.709700 & 98.637500 & 0.216900 \\
\hline-1 & 0.5 & 0.5 & 0.5 & \multirow{3}{*}{0.5} & 0.5 & 0.222300 & 0.334600 & 100 & 0.419900 \\
\hline 0 & 0.5 & 0.5 & 0.5 & & 0.5 & 0.291400 & 0.863700 & 2.048500 & -0.316200 \\
\hline 1 & 0.5 & 0.5 & 0.5 & & 0.5 & 0.531900 & 1.713800 & 84.090300 & 0.310900 \\
\hline-1 & 0.5 & 0.5 & 0.5 & 0.5 & \multirow{3}{*}{0} & 0.082900 & 0.257200 & 0.294200 & 0.342900 \\
\hline 0 & 0.5 & 0.5 & 0.5 & 0.5 & & 0.148800 & 0.735500 & 1.563100 & -0.335900 \\
\hline 1 & 0.5 & 0.5 & 0.5 & 0.5 & & 0.4865 & 1.7111 & 111.7546 & 0.2227 \\
\hline-1 & 0.5 & 0.5 & 0.5 & 0.5 & \multirow{3}{*}{1} & 0.288500 & 0.391200 & 0.488400 & 0.468700 \\
\hline 0 & 0.5 & 0.5 & 0.5 & 0.5 & & 0.360600 & 0.946900 & 2.428900 & -0.279200 \\
\hline 1 & 0.5 & 0.5 & 0.5 & 0.5 & & 0.561700 & 1.716400 & 70.351700 & 0.385700 \\
\hline
\end{tabular}

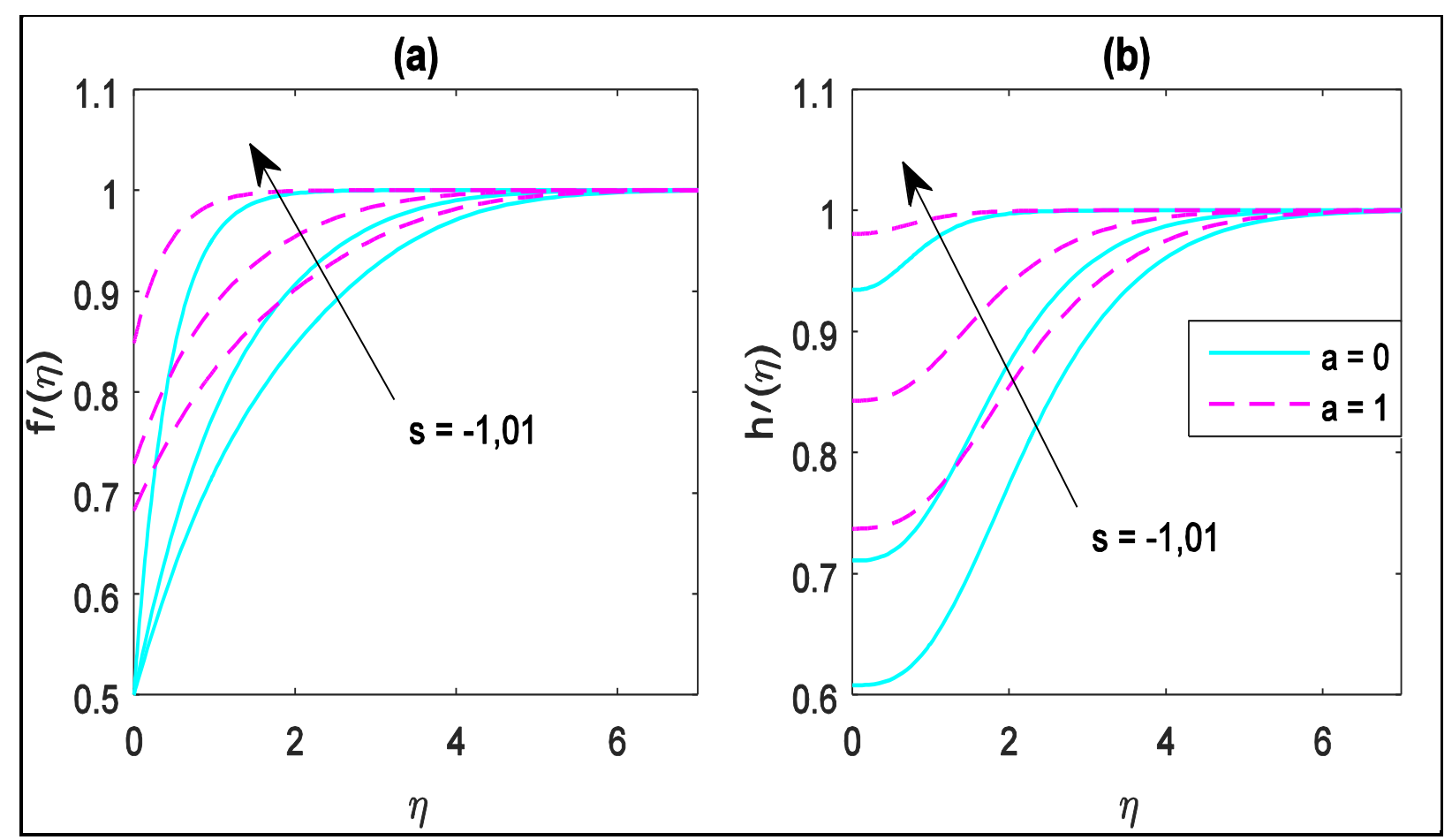

Fig. 2: Profile variation of $f^{\prime}(\eta)$ and $h^{\prime}(\eta)$ with different values of $a$ and $s$. 


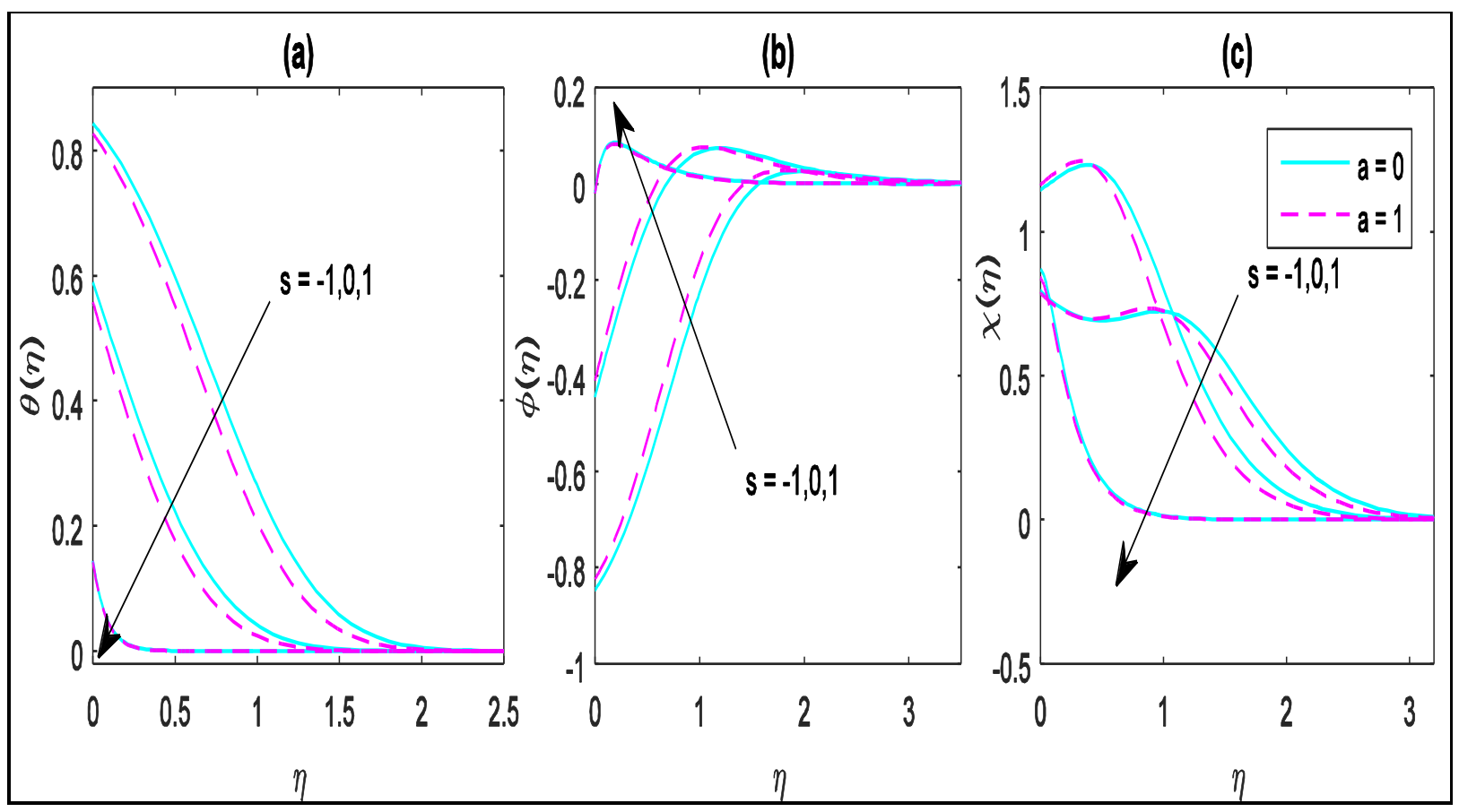

Fig. 3: Profile variation of $\theta(\eta), \phi(\eta)$ and $\chi(\eta)$ with different values of $a$ and $s$.

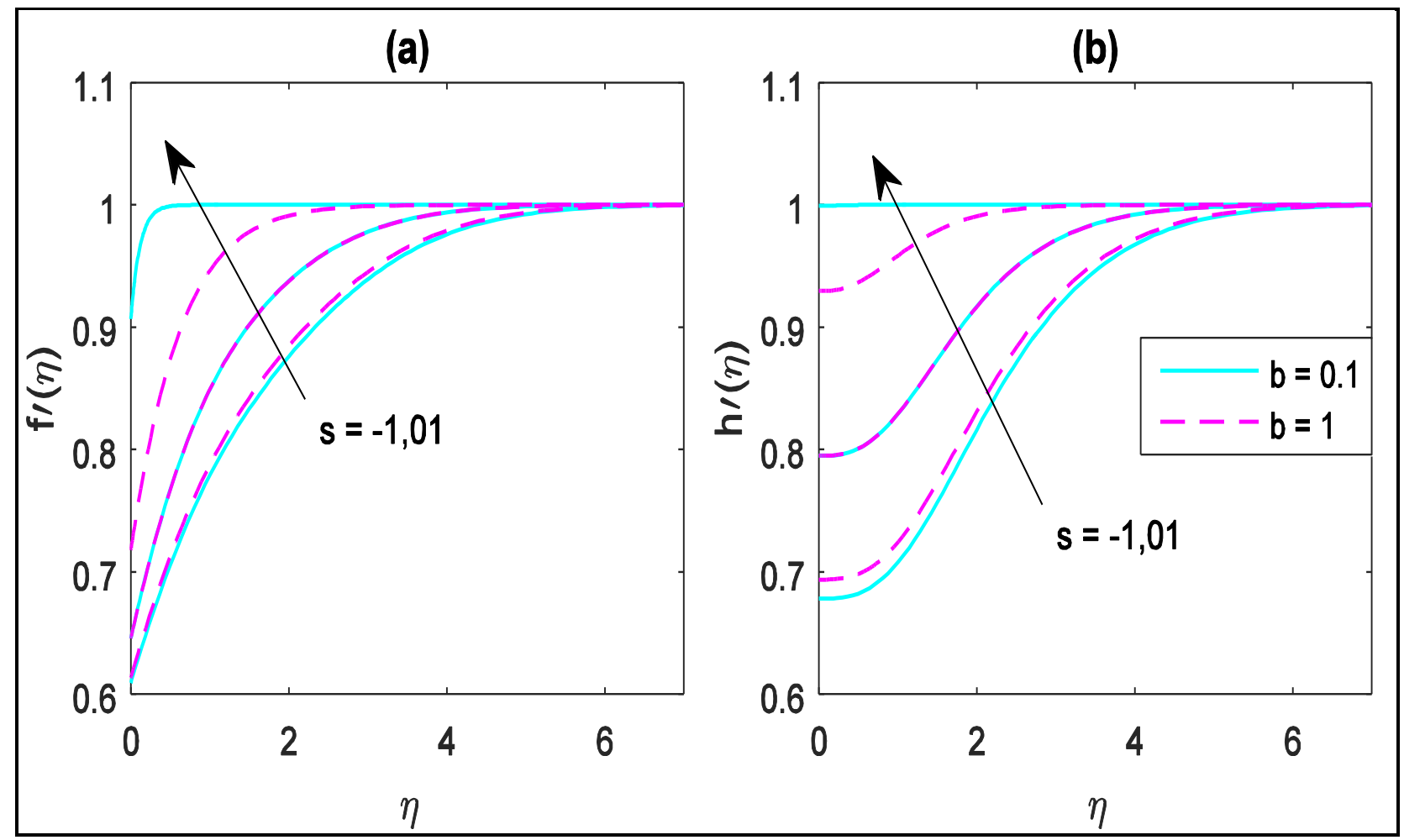

Fig. 4: Profile variation of $f^{\prime}(\eta)$ and $h^{\prime}(\eta)$ with different values of $b$ and $s$ 


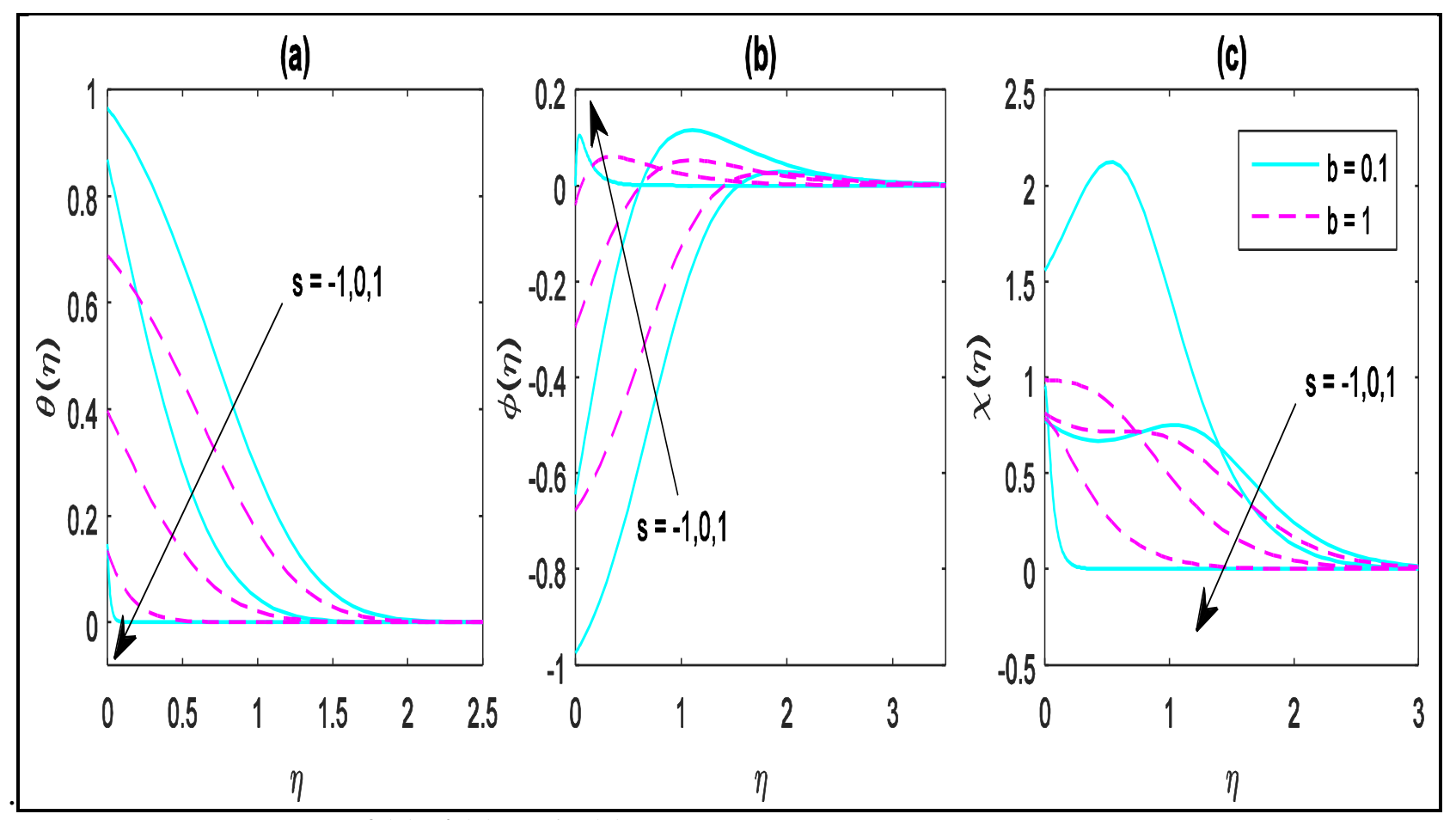

Fig. 5: Profile variation of $\theta(\eta), \phi(\eta)$ and $\chi(\eta)$ with different values of $b$ and $s$.

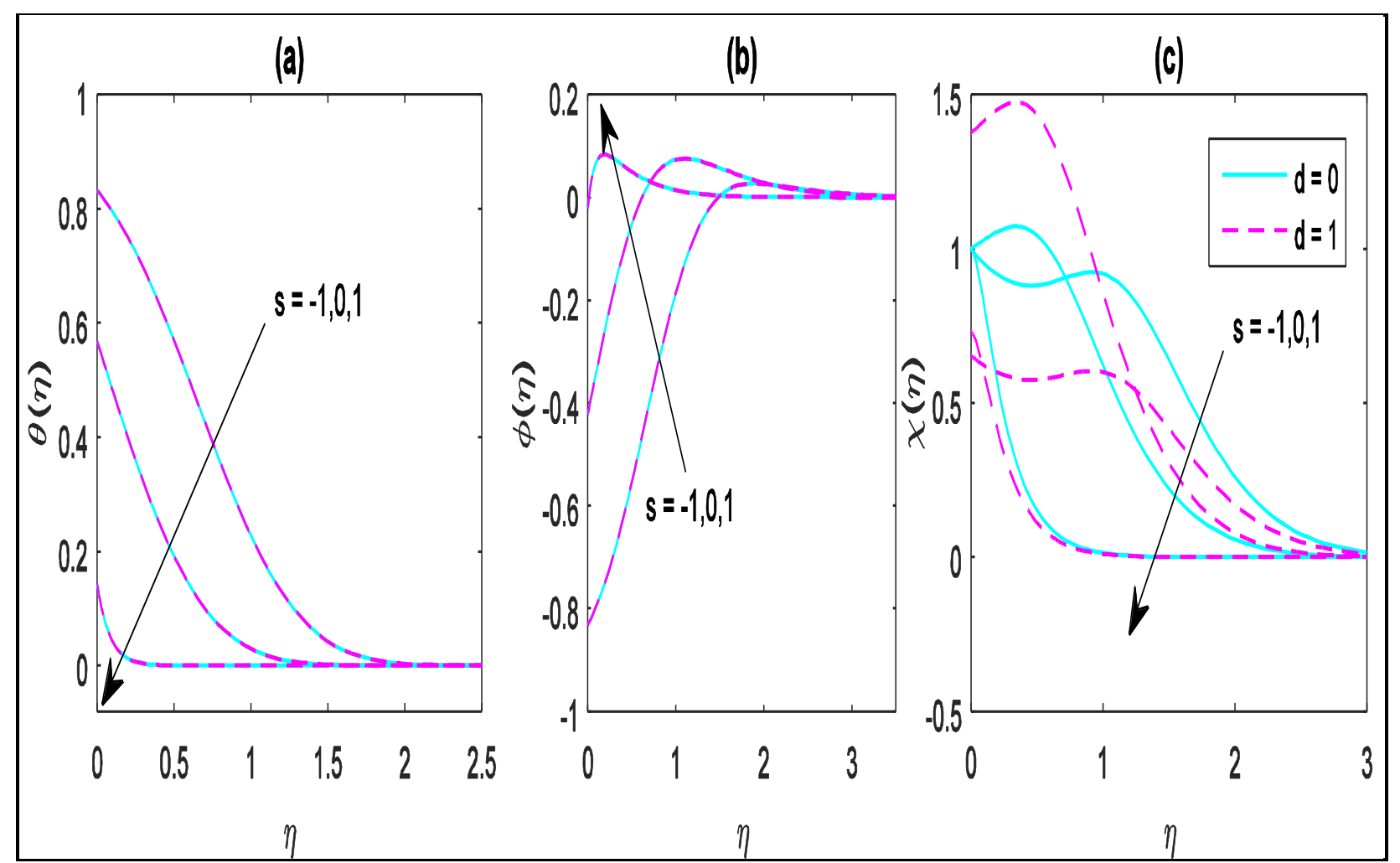

Fig. 6: Profile variation of $\theta(\eta), \phi(\eta)$ and $\chi(\eta)$ with different values of $d$ and $s$. 


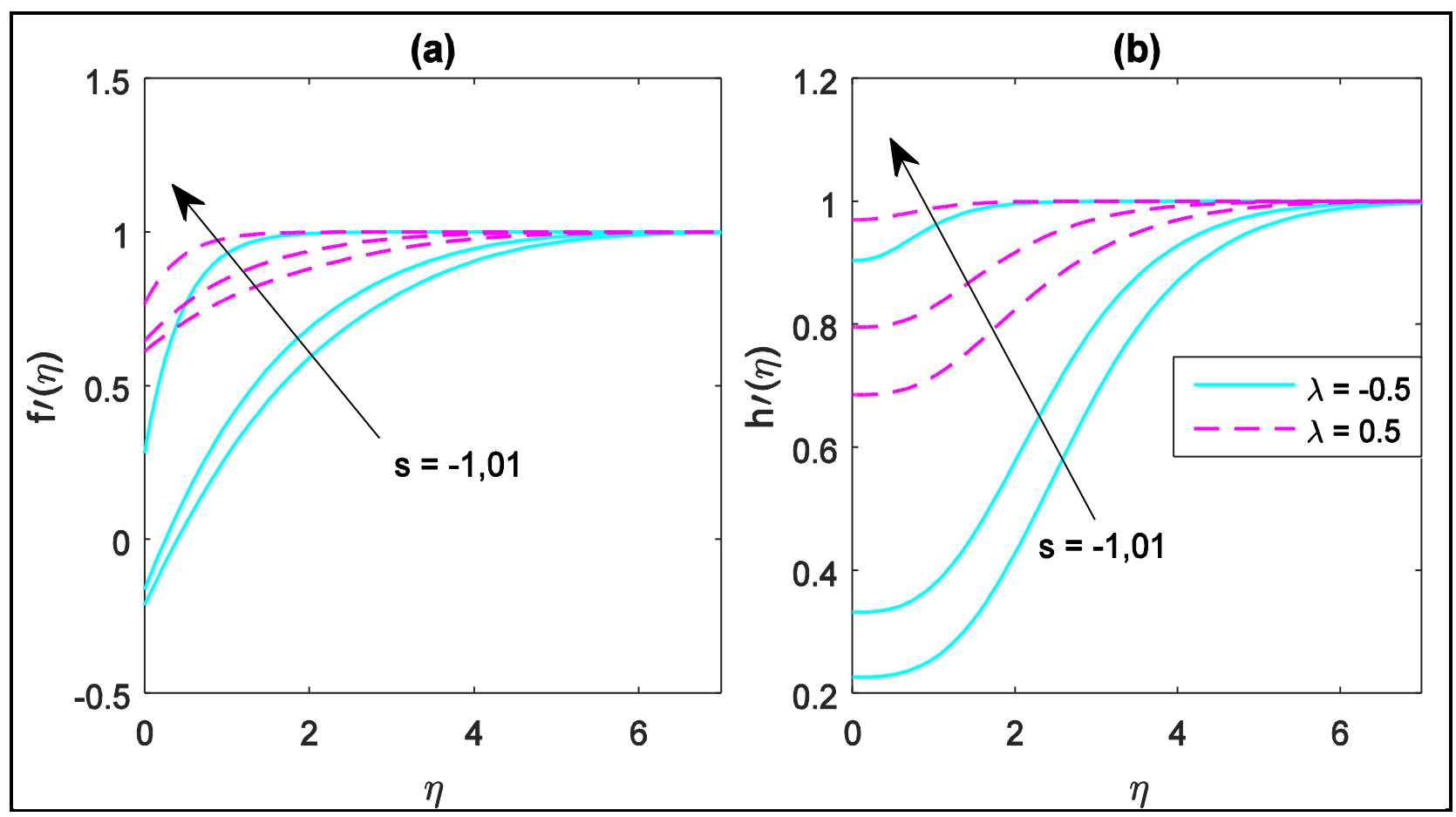

Fig. 7: Profile variation of $f^{\prime}(\eta)$ and $h^{\prime}(\eta)$ with different values of $\lambda$ and $s$.

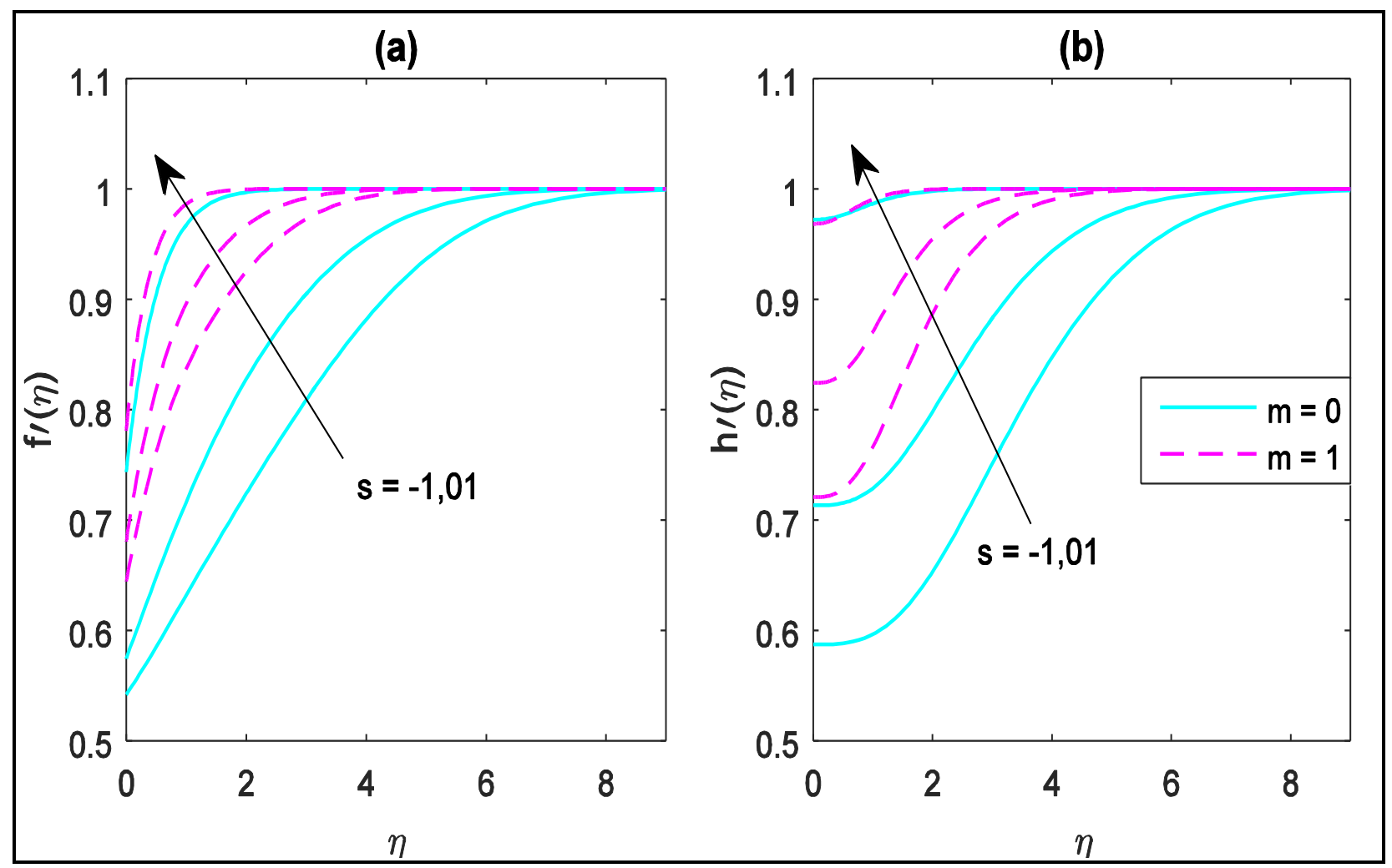

Fig. 8: Profile variation of $f^{\prime}(\eta)$ and $h^{\prime}(\eta)$ with different values of $m$ and $s$. 


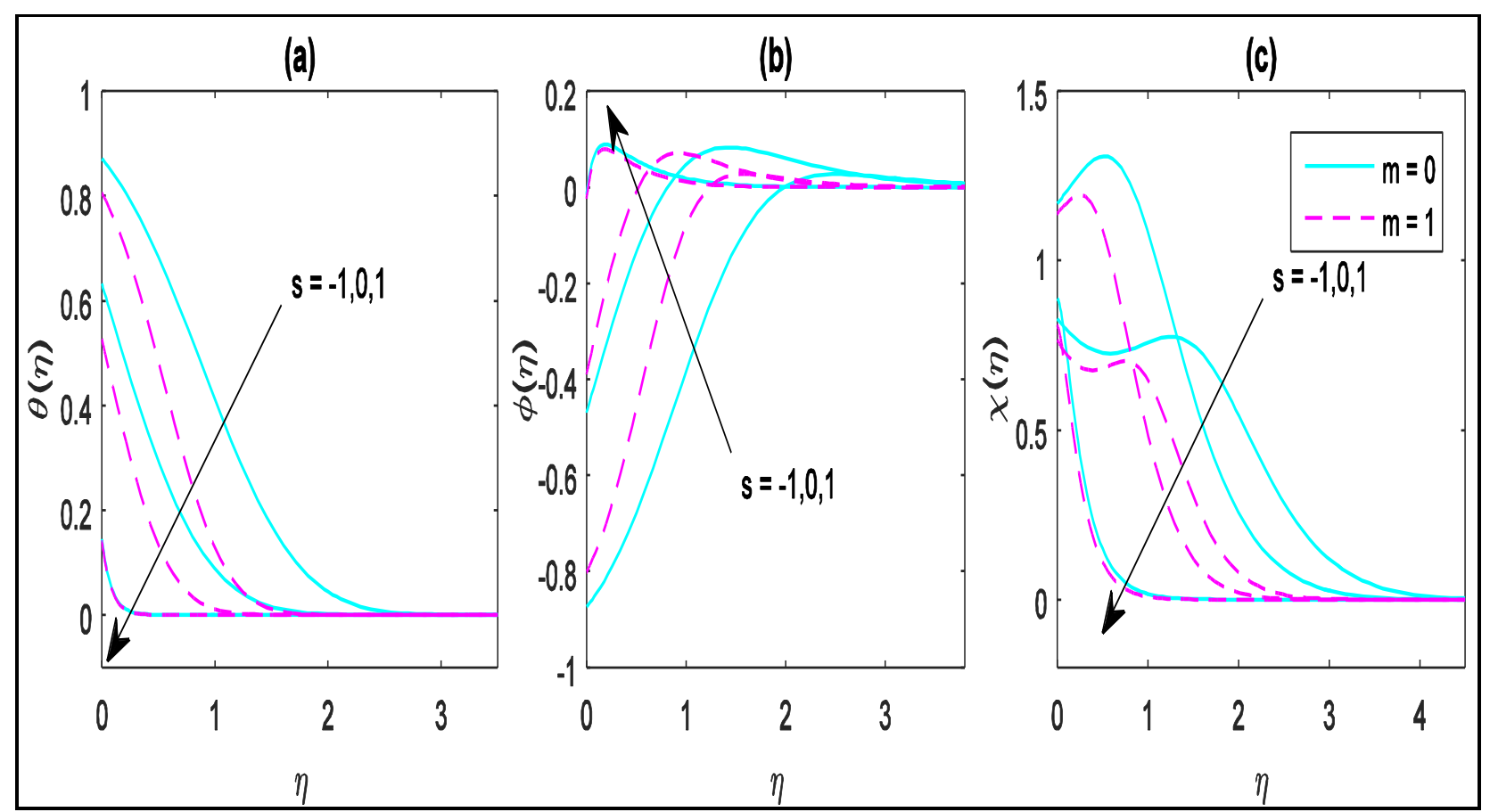

Fig. 9: Profile variation of $\theta(\eta), \phi(\eta)$ and $\chi(\eta)$ due to different values of $m$ and $s$.

Figs. 2(a)-(b) depict the influence of wedge surface suction/blowing parameter, $s$ (i.e. lateral mass flux effect) on the dimensionless velocity and induced magnetic field (magnetic stream function gradient). Figs. 2(a)-(b) clearly demonstrate that both dimensionless velocity and induced magnetic field are boosted with greater Stefan blowing $(s>0)$ whereas they are suppressed in magnitude with greater suction $(s<0)$. Physically with suction at the wall $(s<0)$, nanofluid is drawn through the wall via perforations. This destroys momentum, increases adherence of the boundary layer to the wall and hence declerates the flow which leads to a reduction in momentum (hydrodynamic) boundary layer thickness. With greater injection at the wall $(s>0)$, the opposite effect is generated with a significant accleration of the flow and thinning in the velocity boundary layer thickness. This manifests in a depletion in temperature with stronger suction and an elevation in temperature with stronger injection (blowing). Magnetic induction is indirectly influenced due to coupling of the momentum eqn. (17) and induction eqn. (18) via a number of terms featuring fluid stream function (and its gradient functions) in the latter and several terms featuring magnetic stream function (and its gradient functions) in the former. With greater momentum slip at the wedge surface $(a>0)$ both velocity and magnetic stream function gradient are enhanced. Therefore the momentum and magnetic induction boudnary layer thickness are respectively reduced and increased with enhanced wall hydrodynamic slip. Asympotically smooth convergence of both sets of profiles is attained in the free stream testifying to the prescription of adequately large infinity boundary condition in the computations. Magnitudes of velocity and magnetic stream function gradient are consistently positive indicating that there is never flow reversal or reverse magnetic flux generated in the boundary layer irrespective of wall slip or transpiration condition.

Figs. 3(a)-(c) reveal the effects of wall transpiration $(s)$ and hydrodynamic slip $(a)$ on the temperature , nanoparticle volume fraction and microorganism density functions. It is found that temperature and density of motile microorganism is depressed with an increase in wall blowing $(s>0)$ whereas the nano-particle concentration is enhanced. The reverse trends are generated with wall suction $(s<0)$. Generally positive values of temperature and micro-organism density function are achieved at all locations transverse to the wedge surface. However, only with strong blowing is there positive magnitude present for the nano-particle concentration. Thermal boundary layer thickness is elevated with suction as is micro-organism boundary layer thickness. However, nanoparticle concentration boundary layer thickness is depleted with suction. Increasing 
hydrodynamic slip is also observed to weakly decrease both temperatures and micro-organism density function and the associated boundary layer thicknesses. However greater hydrodynamic slip results in a marked elevation in nano-particle species boundary layer thickness.

Figs. 4(a)-(b) depict the influence of thermal slip $(b)$ and wall transpiration $(s)$ on the dimensionless velocity and induced magnetic field functions. With blowing at the wedge surface $(s<0)$, significant deceleration is generated (i.e. increasing momentum boundary layer thickness) for strong thermal slip $(b=1)$. However with suction at the wedge, a weak acceleration is caused with greater thermal slip. With blowing present, magnetic stream function gradient is noticeably reduced as thermal slip increases. However this is only sustained for a short distance into the boundary layer transverse to the wedge face; thereafter the influence of thermal jump is eliminated. Conversely with suction and thermal slip present, magnetic stream function gradient is clearly elevated. With very low thermal slip $(b=01$.) the magnetic stream function gradient remains invariant with transverse coordinate, irrespective of surface blowing. Effectively the influence of thermal slip is dependent on the wedge surface transpiration condition. For the case of a solid (non-porous) wedge surface there is no tangible alteration in either velocity field or magnetic induction field with thermal jump (slip).

Figs. 5(a)-(c) reveals the response of temperature, nanoparticle volume fraction and density of motile microorganism to thermal slip $(b)$ and wall suction/blowing $(s)$. It is found that temperature and motile microorganism density function are suppressed with an increase in thermal slip. However there is a general elevation in nano-particle concentration with greater thermal slip. These trends are achieved for the case of a porous wedge surface and with either strong blowing or suction at the wall. Therefore weak thermal slip is associated with an increase in thermal and micro-organisms species boundary layer thicknesses whereas it results in a decrease in nano-particle boundary layer thickness.

Figs. 6(a)-(c) depicts the influence of micro-organism slip $(d)$ on the temperature, nanoparticle volume fraction and density of motile microorganism. Temperature and nano-particle concentration functions are insignificantly influenced by the micro-organism slip effect. However motile microorganism density function is substantially decreased with greater micro-organism slip for suction $(s<0)$ or a solid surface of the wedge, whereas it is enhanced with injection (Stefan blowing, $s>0$ ) present at the wedge. Again temperature and microo-organism magnitudes are invariably positive and a maximum at the wedge surface, although there is a weak micro-organism density overshoot with strong blowing regardless of whether thermal slip is imposed or not. Overshoots in nano-particle concentration are also present for all cases of wedge transpiration, although they are progressively displaced closer to the wedge surface as we progress from the suction case to the solid case and then the blowing case. Profiles are also ound to converge asymptotically in the free stream later for the micro-organism density field compared with the temperature and nano-particle concehtration fields.

Figs. 7(a)-(b) depict the combined influence of streaking/shrinking parameter $(\lambda)$ and wall transpiration $(s)$ on the dimensionless velocity and induced magnetic field distributions. The case of a static wedge $(\lambda=0)$ has been considered elsewhere and is omitted. With stretching of the wedge $(\lambda>0)$, greater momentum is imparted to the boundary layer and this serves to accelerate the flow i.e. increase velocity. This also assists in magnetic flux diffusion and enhances the magnetic stream function gradient. Vorticity diffusion and magnetic diffusion are therefore very closely linked in induction flows, although the former is controlled by the Reynolds number and the latter by the magnetic Reynolds number. With contraction of the wedge surface $(\lambda<0)$, momentum is depleted and the external boundary layer flow is impeded. This damps the velocity field and increases momentum (hydrodynamic) boundary layer thickness. The magnetic induction field is also adversely affected and magnetic boundary layer thickness is reduced. These patterns of behavior are enforced for both solid and porous wedges i.e. irrespective of whether blowing or suction are present or both are absent.

Figs. 8(a)-(b) depict the influence of the wedge power-law parameter, $m$, on the dimensionless velocity and induced magnetic field. Two physically viable cases are considered namely for $m=0$ (laminar boundary layer flow from a semi-infinite horizontal surface (Blasius flat plate) and $m=1$ (forward stagnation point flow adjacent to a vertical plate - note, this is also equivalent to the scenario wherein there is linear free stream velocity variation with streamwise distance). The case of a generalized wedge flow, $m>0$ and $m \neq 1$ is considered in a companion article as is rear stagnation-point flow $(m=-1 / 3)$. The generalized wedge boundary 
layer equations therefore reduce in complexity. In particular in the case $m=0$, many terms are eliminated in the momentum boundary layer eqn. (17) i.e. $m\left(K-f^{2}\right)-m M\left(K-h^{2}\right)$. For $m=1$ these terms are retained. A considerable elevation is both velocity and magnetic stream function gradient is caused with an increase in $m$ from 0 to 1 . The forward stagnation case $(m=1)$ therefore achieves strong acceleration and enhancement in the magnetic induction field. Momentum boundary layer thickness is therefore decreased and magnetic boundary layer thickness is enhanced as we progress from the Blasius flat plate case to the vertical plate forward stagnation point case. These responses are sustained whether blowing, a solid wedge surface or suction are imposed.

Figs. 9(a)-(c) depict the influence of wedge power-law parameter $(m)$ on the temperature, nano-particle concentration and motile microorganism density functions. For the vertical plate forward stagnation point case $(m=1)$ both temperature and micro-organism density function are depressed sizeably whereas the nanoparticle concentration is elevated. Nano-particle diffusion is therefore assisted for the vertical plate (i.e. nanospecies boundary layer thickness is increased) whereas thermal diffusion and micro-organism propulsion is inhibited (with associated reductions in the temperature and micro-organsim boundary layer thicknesses). This behaviour is observed for the solid wall (no transpiration) and suction cases. However the opposite effect is induced with injection at the wall. Nano-particle concentrations are found to assume both negative and positive values whereas micro-organism density function magnitudes are consistently positive.

\section{CONCLUSIONS}

Motivated by magnetic nano-materials processing systems, a mathematical model has been developed for magnetohydrodynamic steady two-dimensional bioconvection flow of nanofluids containing gyrotactic micro-organisms over a wedge with velocity slip, thermal jump, zero mass flux and microorganism slip. The Buongiorno nanofluid formulation is adopted. Stefan blowing is taken into account at the wall and magnetic induction effects included. The momentum, induced magnetic field, nano-particle concentration, energy and micro-organism density conservation equations have been transformed into ordinary differential equations (ODEs) by similarity transformations with appropriate boundary conditions. These ODEs constitute a nonlinear coupled boundary-value problem which has been numerically solved with a Chebyshev collocation method using MATLAB software. Details of the numerical calculation are included. Validation with previous special cases from the literature is also performed. A parametric study is conducted to find the influence of slip factors, nanoscale parameters and wedge power-law parameter on the momentum, induced magnetic field, heat, nano-particle and micro-organisms transport phenomena. The computations demonstrate that:

(I)The flow is accelerated with increasing blowing, stretching of the wedge surface, increasing power-law wedge parameter, greater momentum slip whereas it is decelerated with greater thermal slip, contracting of the wedge surface and is invariant to micro-organism slip parameter.

(II) Magnetic induction is elevated with stronger blowing, stretching of the wedge surface, increasing powerlaw wedge parameter, greater momentum slip whereas it is damped with higher thermal slip, wedge contraction and is also unaffected by micro-organism slip parameter.

(III) Temperature is decreased with greater suction, higher power-law wedge parameter, rising thermal slip parameter and momentum slip parameter and is not modified by micro-organism slip parameter.

(IV) Nano-particle concentration is enhanced with greater momentum slip with suction at the wedge and for a solid wedge although it is not influenced tangibly with blowing at the wall. It is also generally increased with greater thermal slip parameter and power-law wedge parameter but not responsive to micro-organism slip effect.

(V) Micro-organism density function is suppressed with increasing power-law wedge parameter, and microorganism slip (for a solid wedge and suction cases) whereas it is enhanced with micro-organism slip when surface injection is present. However, increasing hydrodynamic and thermal slip both reduce the microorganism density function magnitudes i.e. they reduce the micro-organism species boundary layer thickness. 
The current analysis has presented some insight into hydromagnetic induction and slip effects in Falkner-Skan nanofluid bioconvection boundary layer flow. Future investigations will address rheological (e.g. viscoelastic) nanofluids and unsteadiness and will be communicated imminently.

Nomenclature

\begin{tabular}{|c|c|}
\hline $\begin{array}{ll}\mathrm{a} & \text { velocity slip parameter }[-] \\
\mathrm{b} & \text { thermal slip parameter }[-] \\
\bar{b} & \text { chemotaxis constant }[\mathrm{m}]\end{array}$ & $\begin{array}{ll}s & \text { Stefan blowing parameter [] } \\
\text { Sc } & \text { Schmidt number [-] }\end{array}$ \\
\hline$C \quad$ nanoparticle volume fraction [-] & $S h_{\bar{x}}$ the local Sherwood number [-] \\
\hline $\begin{array}{ll}d & \text { microorganism slip parameter }[-] \\
D_{B} & \text { Brownian diffusion coefficient }\left[\mathrm{m}^{2} \mathrm{~s}^{-1}\right]\end{array}$ & $\bar{T} \quad$ nanofluid temperature $[\mathrm{K}]$ \\
\hline$D_{n} \quad$ diffusivity of microorganisms $\left[\mathrm{m}^{2} \mathrm{~s}^{-1}\right]$ & $\begin{array}{l}\bar{u}, \bar{v} \text { velocity components along axes }\left[\mathrm{m} \mathrm{s}^{-}\right. \\
\left.{ }^{1}\right] \\
\bar{x}, \bar{y} \text { Cartesian coordinates along and } \\
\text { normal to the plate }(m)\end{array}$ \\
\hline $\begin{array}{l}D_{1} \quad \text { thermal slip factor }[\mathrm{m}] \\
D_{T} \quad \text { thermophoretic diffusion coefficient } \\
{\left[\mathrm{m}^{2} \mathrm{~s}^{-1}\right]}\end{array}$ & $\begin{array}{l}\tilde{\bar{u}}, \tilde{\bar{v}} \text { average swimming velocity of } \\
\text { microorganisms along axes }\left[\mathrm{m} \mathrm{s}^{-1}\right]\end{array}$ \\
\hline$E_{1} \quad$ microorganism slip factor $[\mathrm{m}]$ & $W_{c}$ maximum cell swimming speed $\left[\mathrm{m} \mathrm{s}^{-1}\right]$ \\
\hline \multicolumn{2}{|l|}{$f(\eta)$ dimensionless stream function[-] } \\
\hline & Greek symbols \\
\hline $\begin{array}{ll}\overline{\mathbf{j}} & \text { vector flux of microorganism }\left[\mathrm{kgm}^{-2}\right. \\
\left.\mathrm{s}^{-1}\right] & \end{array}$ & $\alpha_{m} \quad$ effective thermal diffusivity $\left[\mathrm{m}^{2} \mathrm{~s}^{-1}\right]$ \\
\hline$k \quad$ thermal conductivity $\left[\mathrm{m}^{2} \mathrm{~s}^{-1}\right]$ & $\begin{array}{l}\phi(\eta) \text { rescaled nanoparticle volume fraction [- } \\
]\end{array}$ \\
\hline $\begin{array}{l}\mathrm{h} \text { magnetic stream function [-] } \\
H_{1} \quad \text { induced magnetic field component } \\
\text { along } x \text {-direction }\left(\frac{A}{m}\right) \\
H_{2} \text { induced magnetic field component } \\
\text { along } y \text {-direction }\left(\frac{A}{m}\right)\end{array}$ & $\gamma \quad$ reciprocal of magnetic Prandtl number[-] \\
\hline
\end{tabular}




\begin{tabular}{|c|c|}
\hline $\begin{array}{l}H_{e} \quad \text { magnetic field at the boundary layer } \\
\text { edge }\left(\frac{A}{m}\right)\end{array}$ & \\
\hline & $\begin{array}{l}\chi \quad \text { dimensionless density of motile } \\
\text { microorganisms }(-)\end{array}$ \\
\hline $\begin{array}{ll}L & \text { characteristic length }[\mathrm{m}]\end{array}$ & $\theta(\eta) \quad$ dimensionless temperature[-] \\
\hline$L b \quad$ bioconvection Lewis umber [-] & $\begin{array}{l}v \\
\left.{ }_{1}\right]\end{array}$ \\
\hline Le $\quad$ Lewis number [-] & $\rho_{f} \quad$ fluid density $\left[\mathrm{kg} \mathrm{m}^{-3}\right]$ \\
\hline $\begin{array}{l}\text { M magnetic body force parameter }[-] \\
m \quad \text { wedge parameter [-] }\end{array}$ & $\rho_{p} \quad$ nanoparticle mass density $\left[\mathrm{kg} \mathrm{m}^{-3}\right]$ \\
\hline $\begin{array}{l}n n \text { volume fraction of motile } \\
\text { microorganisms [-] } \\
\mathrm{N}_{1} \quad \text { velocity slip factor }[\mathrm{s} / \mathrm{m}]\end{array}$ & $(\rho c)_{f}$ heat capacity of the fluid $\left[\mathrm{J} \mathrm{kg}^{-3} \mathrm{~K}^{-1}\right]$ \\
\hline $\mathrm{Nb} \quad$ Brownian motion parameter[-] & $\begin{array}{l}(\rho c)_{p} \text { heat capacity of the nanoparticle } \\
\text { material }\left[\mathrm{Jkg}^{-3} \mathrm{~K}^{-1}\right]\end{array}$ \\
\hline $\begin{array}{l}N n_{\bar{x}} \text { local density number of the motile } \\
\text { microorganisms[-] }\end{array}$ & $\begin{array}{l}\tau \quad \text { ratio between the effective heat } \\
\text { capacity of the nanoparticle material and } \\
\text { heat capacity of the fluid [-] }\end{array}$ \\
\hline thermophoresis parameter[-] & \\
\hline$N u_{\bar{x}} \quad$ local Nusselt number [-] & stream function[-] \\
\hline & magnetic diffusivity $\left[\mathrm{m}^{2} / \mathrm{s}\right]$ \\
\hline$P e \quad$ bioconvection Péclet number [-] & Subscripts/superscripts \\
\hline Prandtl number [-] & condition at the wall \\
\hline$p \quad[\mathrm{~Pa}] \quad$ pressure & free stream condition \\
\hline $\operatorname{Re}, \operatorname{Re}_{\bar{x}}$ Reynolds, local Reynold number [-] & differentiation with respect to $\eta$ \\
\hline
\end{tabular}

\section{ACKNOWLEDGEMENTS}

This work is supported by RDU project No. 150391 from University Malaysia Pahang.

\section{REFERENCES}

1. Rosenhead L. Laminar boundary layers: an account of the development, structure, and stability of laminar boundary layers in incompressible fluids, together with a description of the associated experimental techniques. Dover Publications; 1988. 
2. Atalık K and Sönmezler Ü. Symmetry groups and similarity analysis for boundary layer control over a wedge using electric forces. International Journal of Non-Linear Mechanics 2009; 44(8): 883-890.

3. Abdul Gaffar S, Prasad VR, Vijaya B and Beg OA. Mixed Convection Flow of Magnetic Viscoelastic Polymer from a Nonisothermal Wedge with Biot Number Effects. International Journal of Engineering Mathematics 2015; 2015.

4. Rashad AM. Impact of thermal radiation on MHD slip flow of a ferrofluid over a non-isothermal wedge. Journal of Magnetism and Magnetic Materials 2017; 422: 25-31.

5. Olagunju DO. The Falkner-Skan flow of a viscoelastic fluid. International Journal of Non-Linear Mechanics 2006; 41(6): 825-829.

6. Rashidi MM, Rastegari MT, Asadi M and Bég OA. A study of non-Newtonian flow and heat transfer over a non-isothermal wedge using the homotopy analysis method. Chemical Engineering Communications 2012; 199(2): 231-256.

7. Mansutti D, Pontrelli G and Rajagopal KR. Non-similar flow of a non-Newtonian fluid past a wedge. International journal of engineering science 1993; 31(4): 637-647.

8. Yih KA. MHD forced convection flow adjacent to a non-isothermal wedge. International Communications in Heat and Mass Transfer 1999; 26(6): 819-827.

9. Yacob NA, Ishak A and Pop I. Falkner-Skan problem for a static or moving wedge in nanofluids. International Journal of Thermal Sciences 2011; 50(2): 133-139.

10. Ahmad K, Hanouf $\mathrm{Z}$ and Ishak A. MHD Casson nanofluid flow past a wedge with Newtonian heating. The European Physical Journal Plus 2017; 132(2): 87.

11. Ramzan M, Bilal M, Chung JD, Lu DC and Farooq U. Impact of generalized Fourier's and Fick's laws on MHD 3D second grade nanofluid flow with variable thermal conductivity and convective heat and mass conditions. Physics of Fluids 2017;29(9):093102.

12. Ramzan M, Bilal M, Chung JD. Effects of thermal and solutal stratification on Jeffrey magneto-nanofluid along an inclined stretching cylinder with thermal radiation and heat generation/absorption. International Journal of Mechanical Sciences 2017; 131:317-324.

13. Lu DC, Ramzan M, Bilal M, Chung JD, Farooq U. Upshot of Chemical Species and Nonlinear Thermal Radiation on Oldroyd-B Nanofluid Flow Past a Bi-directional Stretched Surface with Heat Generation/Absorption in a Porous Media. Communications in Theoretical Physics 2018;70(1):071.

14. Lu DC, Ramzan M, Bilal M, Chung JD, Farooq U. A Numerical Investigation of 3D MHD Rotating Flow with Binary Chemical Reaction, Activation Energy and Non-Fourier Heat Flux. Communications in Theoretical Physics 2018;70(1):089.

15. Sajid T, Sagheer M, Hussain S, Bilal M. Darcy-Forchheimer flow of Maxwell nanofluid flow with nonlinear thermal radiation and activation energy. AIP Advances 2018;8(3):035102.

16. Bilal M, Sagheer M, Hussain S. On MHD 3D upper convected Maxwell fluid flow with thermophoretic effect using nonlinear radiative heat flux. Canadian Journal of Physics 2017; 96(1):1-10.

17. Sagheer M, Bilal M, Hussain S, Ahmed RN. Thermally Radiative Rotating Magneto-Nanofluid Flow over an Exponential Sheet with Heat Generation and Viscous Dissipation: A Comparative Study. Communications in Theoretical Physics. 2018;69(3):317.

18. Rana P, Uddin MJ, Gupta Y, Ismail AM. Slip effects on MHD Hiemenz stagnation point nanofluid flow and heat transfer along a nonlinearly shrinking sheet with induced magnetic field: multiple solutions. Journal of the Brazilian Society of Mechanical Sciences and Engineering. 2017;39(9):3363-3374.

19. Uddin MJ, Kabir MN, Alginahi YM. Lie group analysis and numerical solution of magnetohydrodynamic free convective slip flow of micropolar fluid over a moving plate with heat transfer. Computers \& Mathematics with Applications. 2015;70(5):846-856.

20. Uddin MJ, Kabir MN, Alginahi YM. Computational investigation of hydromagnetic thermo-solutal nanofluid slip flow in a Darcian porous medium with zero mass flux boundary condition using stretching group transformations. Journal of Porous Media. 2015;18(12).

21. Farooq U, Zhao YL, Hayat T, Alsaedi A and Liao SJ. Application of the HAM-based Mathematica package BVPh 2.0 on MHD Falkner-Skan flow of nano-fluid. Computers \& Fluids 2015; 111: 69-75. 
22. Rashidi MM, Abelman S and Mehr NF. Entropy generation in steady MHD flow due to a rotating porous disk in a nanofluid. International Journal of Heat and Mass Transfer 2013; 62: 515-525.

23. Sheikholeslami M, Ganji DD and Rashidi MM. Magnetic field effect on unsteady nanofluid flow and heat transfer using Buongiorno model. Journal of Magnetism and Magnetic Materials 2016; 416: 164-173.

24. Sheikholeslami M, Rashidi MM, Hayat T and Ganji DD. Free convection of magnetic nanofluid considering MFD viscosity effect. Journal of Molecular Liquids 2016; 218: 393-399.

25. Sheikholeslami M, Vajravelu K and Rashidi MM. Forced convection heat transfer in a semi annulus under the influence of a variable magnetic field. International Journal of Heat and Mass Transfer 2016; 92: 339348.

26. Ali FM, Nazar R, Arifin NM and Pop I. MHD mixed convection boundary layer flow toward a stagnation point on a vertical surface with induced magnetic field. Journal of Heat Transfer 2011; 133(2): 022502.

27. Morton-Jones GJ. Polymer processing. Springer; 1989.

28. Su X, Zheng L, Zhang X and Zhang J. MHD mixed convective heat transfer over a permeable stretching wedge with thermal radiation and ohmic heating. Chemical Engineering Science 2012; 78: 1-8.

29. Rashidi MM, Bég OA, Mehr NF and Rostami B. Second law analysis of hydromagnetic flow from a stretching rotating disk: DTM-Pade simulation of novel nuclear MHD propulsion systems. Frontiers Aerospace Eng. 2013; 2(1): 29-39.

30. Ullah I, Shafie S, Makinde OD and Khan I. Unsteady MHD Falkner-Skan flow of Casson nanofluid with generative/destructive chemical reaction. Chemical Engineering Science 2017; 172: 694-706.

31. Dogonchi AS and Ganji DD. Investigation of MHD nanofluid flow and heat transfer in a stretching/shrinking convergent/divergent channel considering thermal radiation. Journal of Molecular Liquids 2016; 220: 592-603.

32. Mahapatra TR and Gupta AS. Heat transfer in stagnation-point flow towards a stretching sheet. Heat and Mass transfer 2002; 38(6): 517-521.

33. Gupta D, Kumar L, Bég OA and Singh B. Finite element simulation of nonlinear magneto-micropolar stagnation point flow from a porous stretching sheet with prescribed skin friction. Computational Thermal Sciences: An International Journal 2015; 7(1), 1-14.

34. Khan MI, Kiyani MZ, Malik MY, Yasmeen T, Khan MW and Abbas T. Numerical investigation of magnetohydrodynamic stagnation point flow with variable properties. Alexandria Engineering Journal 2016; 55(3): 2367-2373.

35. Khan ZH, Khan WA, Qasim M and Shah IA. MHD stagnation point ferrofluid flow and heat transfer toward a stretching sheet. IEEE Transactions on Nanotechnology 2014; 13(1): 35-40.

36. Bég OA, Prasad VR and Vasu B. Numerical study of mixed bioconvection in porous media saturated with nanofluid containing oxytactic microorganisms. Journal of Mechanics in Medicine and Biology 2013; 13(04): 1350067.

37. Gireesha BJ, Mahanthesh B, Shivakumara IS and Eshwarappa KM. Melting heat transfer in boundary layer stagnation-point flow of nanofluid toward a stretching sheet with induced magnetic field. Engineering Science and Technology, an International Journal 2016; 19(1): 313-321.

38. Begum N, Siddiqa S and Hossain MA. Nanofluid bioconvection with variable thermophysical properties. Journal of Molecular Liquids 2017; 231: 325-332.

39. Das K, Duari PR and Kundu PK. Nanofluid bioconvection in presence of gyrotactic microorganisms and chemical reaction in a porous medium. Journal of Mechanical Science and Technology 2015; 29(11): 4841-4849.

40. Shaw S, Kameswaran PK, Narayana M and Sibanda P. Bioconvection in a non-Darcy porous medium saturated with a nanofluid and oxytactic micro-organisms. International Journal of Biomathematics 2014; 7(01): 1450005.

41. Uddin MJ, Kabir MN and Bég OA. Computational investigation of Stefan blowing and multiple-slip effects on buoyancy-driven bioconvection nanofluid flow with microorganisms. International Journal of Heat and Mass Transfer 2016; 95: 116-130. 
42. Basir MFM, Uddin MJ, Md. Ismail AI and Bég OA. Nanofluid slip flow over a stretching cylinder with Schmidt and Péclet number effects. AIP Advances 2016; 6(5): 055316.

43. Kuznetsov AV. Nanofluid bioconvection: interaction of microorganisms oxytactic upswimming, nanoparticle distribution, and heating/cooling from below. Theoretical and Computational Fluid Dynamics 2012; 26(1): 291-310.

44. Kuznetsov AV and Nield DA. Natural convective boundary-layer flow of a nanofluid past a vertical plate: A revised model. International Journal of Thermal Sciences 2014; 77: 126-129.

45. Sutton GW and Sherman A. Engineering magnetohydrodynamics. McGraw-Hill; 1965.

46. Dehghan M, Mahmoudi Y, Valipour MS and Saedodin S. Combined conduction-convection-radiation heat transfer of slip flow inside a micro-channel filled with a porous material. Transport in Porous Media 2015;108(2): 413-436.

47. Dorfman, AS. Conjugate Problems in Convective Heat Transfer. CRC Press, UK; 2010.

48. Uddin MJ, Alginahi Y, Bég OA and Kabir MN. Numerical solutions for gyrotactic bioconvection in nanofluid-saturated porous media with Stefan blowing and multiple slip effects. Computers \& Mathematics with Applications 2016; 72(10): 2562-2581.

49. Jafar K, Nazar R, Ishak A and Pop I. MHD boundary layer flow due to a moving wedge in a parallel stream with the induced magnetic field. Boundary Value Problems 2013; 2013(1): 20.

50. Kuo BL. Heat transfer analysis for the Falkner-Skan wedge flow by the differential transformation method. International Journal of Heat and Mass Transfer 2005; 48(23): 5036-5046. 